\title{
COMPETIR EN LOS MERCADOS INTERNACIONALES. ALTOS HORNOS DE VIZCAYA, 1882-1936*
}

\section{STEFAN HOUPT}

Universidad Carlos III de Madrid

\section{RESUMEN}

El propósito de este trabajo es el de proporcionar un análisis comparativo de la actuación empresarial productiva de la moderna industria siderúrgica española desde sus inicios hasta la Guerra Civil Española. Se estudian tres aspectos: en qué medida la industria tuvo el potencial para competir en los mercados mundiales, si las fábricas aplicaron las innovaciones que podrian haber reestablecido o mantenido su competitividad e identificar los elementos que limitaban o incrementaban la competitividad de sus productos en el exterior. El estudio muestra una «ventaja revelada» de los productos intensivos en mineral de hierro. Parte de la ventaja comparativa provenía de contratos preferenciales de suministro de mineral. A su vez, estos contratos eran limitados e introducían unos fuertes incentivos para no aumentar la escala de producción. El origen de la captación de los mercados nacionales por parte de la empresa dominante, Altos Hornos de Vizcaya, podría residir en esta limitación. Los elevados beneficios que aportaban, por un lado, la cartelización del sector y, por otro lado, el generoso margen de beneficio que implicaba producir dentro de la escala de los contratos preferenciales de mineral, dan una explicación alternativa a la actuación de la siderurgia española en este período.

$N$. de E.: Fecha de recepción del artículo: mayo,-2002.

Fecha de aprobación por el Consejo de Redacción: mayo, 2003.

* Quiero agradecer las sugerencias que ha suscitado este trabajo, en especial las de Joan R. Rosés y Antonio Tena, y los dos evaluadores anónimos. 


\section{ABSTRACT}

This article presents a comparative analysis of the productive performance of the modern Spanish iron and steel industry from its origins up to the Spanish Civil War. Three aspects are examined: the extent to which the industry had the potential to compete in world markets, whether or not Spanish mills applied new technologies to re-establish or maintain their competitivity and which elements limited or increased the advantage of their products. The analysis shows a revealed advantage in products intensive in iron ore. Part of this advantage can be traced back to preferential ore supply contracts. The limits to these preferential contracts introduced incentives for maintaining the reduced scale of Spanish installations. The attempt to gain control over home markets on behalf of Altos Hornos de Vizcaya may be related to these contractual limitations. The high profits reaped through the cartelisation of the industry and the wide margin of benefit obtained by producing within the scale of the preferential ore supply contracts provide an alternative explanation for the industry's performance in the period.

JEL Classification: N63, N83, O14.

\section{INTRODUCCIÓN}

La historiografía económica de la siderurgia moderna - la producción integrada de productos de hierro y sobre todo acero- es extensa. Pero mientras sus investigaciones más relevantes se han centrado en el análisis de crecimiento, las estrategias empresariales y las innovaciones en Gran Bretaña, Alemania y Estados Unidos ${ }^{1}$, existen en la actualidad pocos trabajos acerca de aquellos países que establecieron sus propias industrias del acero con la pretensión de seguir el camino de los países más avanzados $^{2}$.

Entre estos países seguidores, el caso español plantea uno de los casos de mayor interés. El papel de España en la producción mundial de hierro y acero desde el último cuarto del siglo XIX hasta la segunda década del siglo $\mathrm{Xx}$ ha sido muy significativo, consistiendo, fundamentalmente, en suministrar minerales de hierro a las principales siderurgias europeas. La importancia de los hematites españoles aumentó con la escasez de minerales de hierro bajos en fósforo en países de demanda creciente como Gran Bretaña, Alemania y Bélgica o incluso Estados Unidos. A partir de 1868,

${ }^{1}$ Para citar algunos, Beck (1903), Burn (1940), Burnham y Hoskins (1943), Carr y Taplin (1962), Temin (1964), Hogan (1971), McCloskey (1973), Feldenkirchen (1982), Wengenroth (1986) y Kennedy (1987).

2 Baer (1969), Nilsson (1972) y Okazaki (1991). 
la liberalización paralela de la legislación minera española ayudó a desmantelar algunas de las barreras regionales e internacionales al comercio y sirvió para atraer la inversión al sector minero, sobre todo en Vizcaya. Estas circunstancias, unidas a la demanda creciente de carriles de acero Bessemer desde la década de 1860 , dieron los incentivos y abrieron las oportunidades necesarias para explotar masivamente los minerales de hierro españoles, y España llegó a extraer el 8 por 100 del mineral de hierro mundial entre 1882 y $1922^{3}$.

El papel pequeño pero significativo de la minería de hierro española dentro del contexto industrial de la siderurgia mundial no trascendió al sector de transformación de hierro y acero, donde la industria nacional produjo tan sólo el 0,7 por 100 de la producción mundial para el mismo período ${ }^{4}$. Con más de dos terceras partes de la capacidad industrial concentrada en las modernas fábricas de la provincia de Vizcaya y las mayores reservas de carbón del país - las de Asturias y León- relativamente cercanas, resulta difícil entender el papel secundario desempeñado por España en la producción mundial de productos del hierro y el acero. Muchos contemporáneos ya resaltaron la ventaja comparativa española en este sector, manteniéndose esta leyenda de las oportunidades perdidas hasta nuestros días ${ }^{5}$. Alrededor del debate sobre lo que pudo ser pero nunca fue, se desarrollaron diversas teorías para justificar el fracaso de la industria. Las dos principales explicaciones atribuyen el subdesarrollo del sector, o a la falta de demanda interna, o a los vicios de la búsqueda de rentas. Ambos planteamientos se mueven dentro de un modelo de economía cerrada. Frente a dichas posturas, este trabajo plantea una cuestión previa: chasta qué punto era factible producir para los mercados internacionales desde España? El análisis del sector parte del principio según el cual la mejor forma de juzgar la competitividad de cualquier industria es su ventaja comparativa internacional.

La concentración de la industria española facilita nuestro análisis. Hacia finales del siglo XIX, las tres siderurgias más modernas de España se encontraban en Vizcaya. Solamente dos de estas plantas vizcaínas sobrevivieron,

${ }^{3}$ Escudero (1998), p. 305, contrastado con Barreiro Zabala (1943) y Carr y Taplin (1962).

${ }^{4}$ Barreiro Zabala (1943), Churraca (1951), Burnhham y Hoskins (1943) y Carr y Taplin (1962). Cálculos propios para el siglo XIX.

5 Alzola y Minondo (1896, p. 55) compara la exportación del mineral vasco - como alternativa a su transformación en productos de mayor valor añadido- con la inconsciencia de Esaú, que vendió sus derechos de primogénito por un plato de lentejas. Véase también Adaro Magro'(1885), p. 175. 
fusionándose en una única empresa en 1901 -Altos Hornos de Vizcaya-. Altos Hornos de Vizcaya, a su vez, absorbió los restos de la tercera siderurgia en los años veinte. Otras fábricas, como las asturianas, leonesas o andaluzas, presentaban serios inconvenientes para considerar si podían competir internacionalmente: las elevadas ratios de fundente necesarias en sus cargas, la mala coquización de sus carbones, sus equipos obsoletos, sus deficientes instalaciones portuarias y las dificultades de transporte terrestre. Estas circunstancias disparaban su coste de poner en el mercado un producto comparable al vasco y justifica su exclusión en este análisis ${ }^{6}$.

Realmente la única amenaza seria al predominio de Altos Hornos de Vizcaya surgió en los años veinte, cuando capitalistas vascos integraron hacia adelante sus minas de Teruel y Guadalajara con una planta siderúrgica en Sagunto (Valencia) ${ }^{7}$. Sin embargo, las adversidades del período de entreguerras impidieron las economías estratégicas: proyectaron la importación provechosa de carbones como lastre de retorno a las exportaciones de una gran parte del mineral a países como Alemania y Gran Bretaña. La coyuntura poco dinámica de estos mercados después de la Primera Guerra Mundial llevó a la Compañía Siderúrgica del Mediterráneo a la quiebra. Muchos años después, a finales de los años cincuenta, la intervención directa del Estado a través del Instituto Nacional de Industria y dentro de su marco político de autarquía económica, estableció otra alternativa seria a la producción vizcaína con la planta integral de ENSIDESA en Avilés (Asturias) ${ }^{8}$. Así, las fábricas vizcaínas se convertirían a lo largo del período analizado - de 1882 a 1936 - en las empresas dominantes de España, vendiendo más del 50 por 100 de la mayor parte de los productos ${ }^{9}$. De no haberse impuesto restricciones oligopolísticas, su participación en el mercado nacional podía haber sido mayor aún. Prácticamente todas las empresas siderúrgicas participaban en los cárteles de venta desde finales del siglo XIX, esta colusión se institucionalizó en la primera década del siglo Xx con el cártel de ventas, Central Siderúrgica, liderado por Altos Hornos de Vizcaya como empresa dominante ${ }^{10}$.

- Véase Houpt (2002) para una discusión acerca de la localización óptima de la industria siderúrgica en este período.

7 Véase Girona Rubio (1989) o Torres Villanueva (1998).

${ }^{8}$ Martín Aceña y Comin (1991), pp. 170-177.

9 Calculado con Houpt (1998), vol. II, y los datos de Barreiro Zabala (1943).

${ }^{10}$ Fraile (1991), pp. 129-139, y González Portilla (1985a) y (1985b), pp. 191-235. Véase Sáez García (1999, pp. 124-142) para los primeros acuerdos colusivos del sector siderúrgico. 
Dada la clara superioridad técnica de las fábricas vizcaínas sobre las otras plantas españolas, su análisis nos permitirá saber si el sector siderúrgico español era capaz de competir en los mercados internacionales. Existe una historiografía amplia acerca de las fábricas bilbaínas. Entre los más prolíficos, Manuel González Portilla ha publicado varios trabajos sobre la historia de Altos Hornos de Vizcaya y las empresas antecesoras. González Portilla desarrolla un análisis de los orígenes y la actuación de las plantas vizcaínas, de su evolución hacia la cartelización del sector, y también estudia los costes de algunos de sus productos y materias primas ${ }^{11}$. Una segunda vertiente de trabajos sobre la siderurgia vasca moderna son los trabajos de Emiliano Fernández de Pinedo. En ellos estudia salarios, inversiones e innovación durante las primeras décadas de la empresa. Además, Fernández de Pinedo vuelve a analizar sus orígenes y recalcula los beneficios obtenidos ${ }^{12}$. Ha habido también otras incursiones en la siderurgia vasca. Joseph Harrison ha investigado su relación con la intervención del Estado, y Pedro Fraile ha expuesto los efectos de la búsqueda de rentas sobre la industria ${ }^{13}$. Finalmente, los trabajos de Luis Barreiro, Francisco Sánchez Ramos, Eustaquio Fernández-Miranda e Higinio París Eguilaz reúnen información estadística detallada a nivel agregado para la producción nacional y regional ${ }^{14}$.

Sin embargo, ninguno de los trabajos anteriores ha tratado de analizar la industria dentro de un contexto de economía abierta. Descifrar hasta qué punto era factible producir para los mercados internacionales desde España - en vez de ejercer presiones para imponer aranceles prohibitivos, cartelizar al sector y captar los mercados nacionales- sigue siendo una pregunta abierta. El propósito de este trabajo es el de proporcionar un análisis comparativo de la actuación empresarial productiva de la moderna industria siderúrgica vasca desde sus inicios, a mediados de la década de los 1880, hasta la Guerra Civil Española ${ }^{15}$. Las cuestiones principales a tratar serán las de identificar y medir el alcance de las ventajas comparativas de España en la producción de hierro y acero, y ver cómo evolucionaron estas ventajas en el tiempo. Nuestro análisis se plantea las siguientes preguntas: ¿tenía la industria siderúrgica nacional el potencial para competir

"González Portilla (1974), (1981), (1984), (1985a), (1985b) y (1993).

12 Fernández de Pinedo (1983), (1987), (1988) y (1992).

13 Harrison (1976) y (1983) y Fraile (1991) y (1992).

${ }^{14}$ Barreiro Zabala (1943), Sánchez Ramos (1945), Fernández-Miranda (1925) y París Eguilaz (1954).

${ }^{15}$ Con la Guerra Civil se inicia un periodo de autarquia e intervención económica que dificulta eł análisis en los términos aquí planteados. 
en los mercados mundiales?, caplicaron las fábricas las innovaciones que podrían haber reestablecido o mantenido su competitividad en los mercados internacionales?, y cqué factores limitaban o incrementaban la competitividad de sus productos en el exterior?

\section{COMPETIR EN LOS MERCADOS MUNDIALES}

La primera cuestión, la identificación de las ventajas comparativas en las diferentes líneas de producto, se contrastará a través de los datos extraídos para las dos fábricas de Altos Hornos de Vizcaya. Los precios de coste se compararán con precios de mercado de los Estados Unidos, Alemania, Gran Bretaña y Bélgica. Estas comparaciones nos permitirán identificar líneas de productos con ventajas comparativas: las transformaciones primarias como el lingote de hierro, el acero y los carriles; y otras líneas de producto con desventajas evidentes, como es el caso de las transformaciones secundarias: planchas, chapas, planos y otros productos de mayor grado de transformación.

El gráfico 1 compara el coste medio de fábrica en Bilbao con el promedio de los precios de mercado de las plazas más importantes en Europa y América. Valores inferiores a uno indican que el precio de coste en Bilbao se situaba por encima del precio de mercado mundial; por el contrario, valores por encima de uno muestran la ventaja que tenía el precio de coste de Bilbao frente a los precios de mercado. Así, por ejemplo, la ratio 1,65 para el lingote de hierro indica que el precio de mercado del lingote en las demás plazas era un 65 por 100 más caro que el lingote a precio de fábrica en Bilbao. Observamos que el precio del lingote de hierro vizcaíno muestra un ventaja de entre un 10 y un 50 por 100 frente al promedio en el extranjero. El siguiente producto en orden de intensidad de transformación, el raíl de acero de Altos Hornos de Vizcaya, muestra entre un 20 y un 40 por 100 de margen. Las estadísticas de comercio exterior, que reflejan exportaciones netas importantes para estos dos productos, y los datos extraídos de las empresas más grandes, confirman este extremo. Asimismo, la última revisión de Escudero (1999) sitúa la exportación del lingote vizcaíno en un 24,8 por 100 de la producción entre 1881 y 1900 . Esto contrasta con los datos de González Portillo (1985, p. 169) para la empresa La Vizcaya, que exportó un promedio del 45 por 100 del lingote producido entre 1886 y 1901. Algo parecido sería el caso de la fábrica de San Francisco de Mudela, que exportaba 


\section{GRÁFICO 1}

Promedio de ratios entre precios de fábrica en Bilbao $y$ precios de mercado de las principales plazas siderúrgicas mundiales

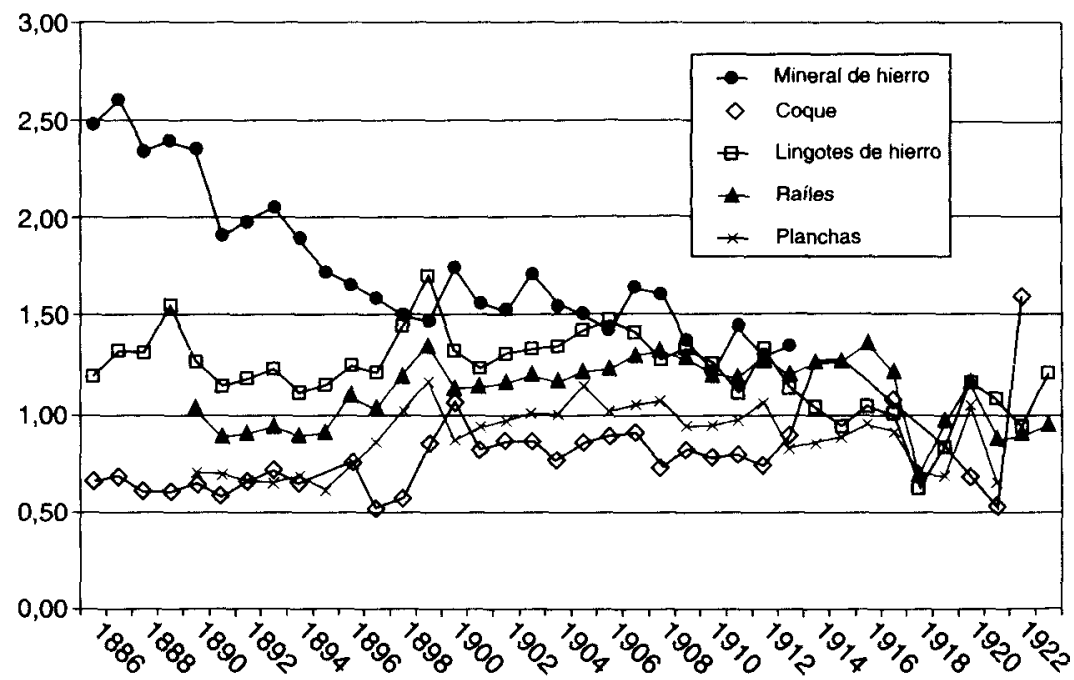

Fuente: Houpt (1998), vol. I, Apéndice C, pp. 28-35.

NOTA: Los promedios de precios de mercado son medias aritméticas para:

a) Mineral de bierro. Northeast Coast Spanish rubio, Northeast Coast Cleveland núm. 3, Northwest Coast Cumberland, Northwest Coast Spanish rubio, Ruhr minettes, Swedish basic, Pittsburgh Old Range y Mesabi.

b) Coque. North Yorkshire, Middlesbrough Durham, West Coast Durham, Pittsburgh Conneilsville y Ruhr Westphalian.

c) Lingote de bierro. Ruhr, Pittsburgh, promedio británico Mitchell, Cleveland fob, Cumberland hematite y Cumberland fob.

d) Railes. North Yorkshire, Cumberland, exportaciones británicas, promedio fábrica británico, expcrtaciones alemanas, Westfalia, promedio fábrica alemán, exportaciones belgas, Pennsylvania, exportaciones estadounidenses y promedio británico Mitchell.

e) Planchas. Escocia, North Yorkshire, exportaciones alemanas, Pittsburg, Middlesbrough y promedio británico Mitchell.

un promedio de $34.000 \mathrm{tm}$ entre 1888 y 1891 . Aun así, aunque las discrepancias entre fuentes no aconsejan un uso más allá del indicativo de los datos, el gráfico 2 sirve para dar una idea de la evolución de la salida 


\section{GRÁFICO 2}

Exportación de bierro y acero. España 1869-1936

(Toneladas métricas)

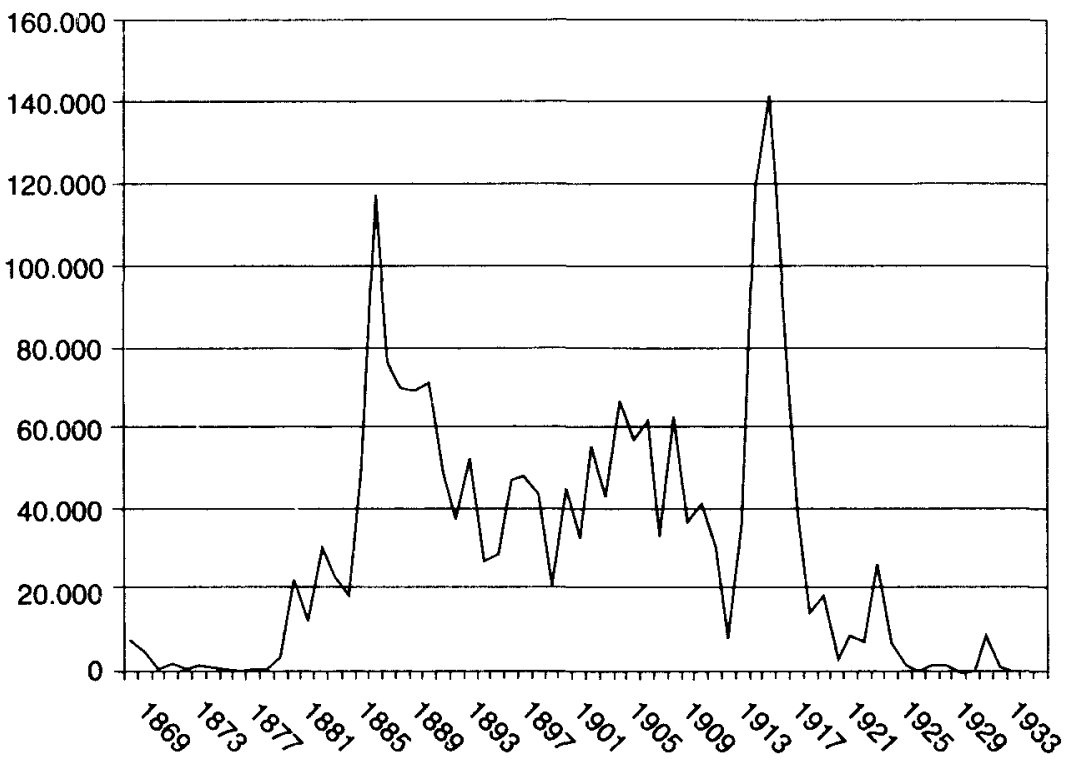

Fuente: Estadísticas de Comercio Exterior de España. Dirección General de Aduanas. Ministerio de Hacienda.

NoTA: La serie recoge para:

1869-1876 Hierro toda clase.

1877-1882 $\Sigma$ (Hierro colado en lingotes) + (hierro forjado barras) + (demás hierros y herramientas).

1883-1906 $\Sigma$ (Hierro colado en lingotes) + (hierro forjado barras) + (hierros y aceros manufacturados en cualquier otra forma).

1907-1936 (Hierro colado en lingotes) $+\Sigma$ hierro y acero manufacturado de todas clases.

de productos siderúrgicos basándonos en las estadísticas de comercio exterior entre 1869 y $1936^{16}$.

Aparte de la competitividad manifiesta del lingote y los raíles que se reflejan en ambos gráficos, el primer gráfico muestra una tendencia adi-

${ }^{16}$ Existe, por ejemplo, una diferencia del 24 por 100 entre los datos de exportación de lingote de las estadísticas del comercio exterior y los de las Memorias de la Junta del Puerto de Bilbao entre 1887 y 1899. 
cional: el margen positivo entre el precio promedio de los productos europeos y el precio de fábrica en Bilbao se va reduciendo a medida que aumenta el grado de transformación del producto. Es muy alto para hierro bruto - mineral de hierro-, sigue siendo importante para la primera transformación -lingote de hiero-, incluso hay un pequeño margen para un producto de segunda transformación sencillo - los raíles-. Pero las segundas transformaciones más intensivas en carbón -las planchas - muestran ya poco margen para competir. La ventaja comparativa de los productos vizcaínos - muy en línea con lo que predice el modelo de Heckscher-Ohlin- procede de su intensidad en mineral de hierro. A medida que aumenta el grado de transformación se reduce esta intensidad del factor mineral de hierro con el creciente impacto de la carestía relativa del combustible sobre el precio final del producto.

Los siguientes gráficos contrastan esta hipótesis sostenida por la historiografía española desde hace tiempo: España tenía desde finales del siglo XIX una ventaja comparativa en productos intensivos en mineral de hierro y sufría una competitividad decreciente a medida que aumentaba la intensidad de carbón en sus productos ${ }^{17}$. El gráfico 3 muestra el consumo unitario de mineral de hierro y de carbón en Altos Hornos de Bilbao en 1897 para distintos productos siderúrgicos. A medida que nos desplazamos de izquierda a derecha en el gráfico, aumenta el grado de transformación del producto y consecuentemente la intensidad relativa de carbón y hierro empleada para obtener una tonelada del producto en cuestión. Observamos que, a mayor grado de transformación, los productos se hacen relativamente más intensivos en carbón y menos intensivos en mineral de hierro, lo que conlleva una pérdida de la ventaja comparativa de la que gozaba España por ser un país con abundancia de mineral de hierro. El gráfico 4 es el resultado de multiplicar las cantidades de consumo unitario por sus precios en Bilbao y Gran Bretaña respectivamente y sumarlos como coste unitario en ambos emplazamientos. En ambas ubicaciones, el mineral de hierro que se utiliza es español, y el carbón, británico. El gráfico refleja menor coste total para los productos intensivos en mineral de hierro para el caso de España, mientras lo contrario es cierto para productos intensivos en carbón, donde Gran Bretaña tiene un menor coste relativo.

Los gráficos dejan a un lado los demás factores de producción: trabajo, capital y otros materiales. Pero los factores de producción omitidos suma-

17 Nadal (1989), p. 187; Fernández de Pinedo (1983), pp. 13.16; Fernández de Pinedo (1987), p. 154; Fernández de Pinedo (1988), pp. 257-258; González Portilla (1981), p. 119, y González Portilla (1985a), pp. 161-168. 


\section{GRÁFICO 3 \\ Toneladas de mineral de bierro y de carbón consumidos por tonelada de producto final en Altos Hornos de Bilbao, 1897 \\ (Toneladas métricas)}

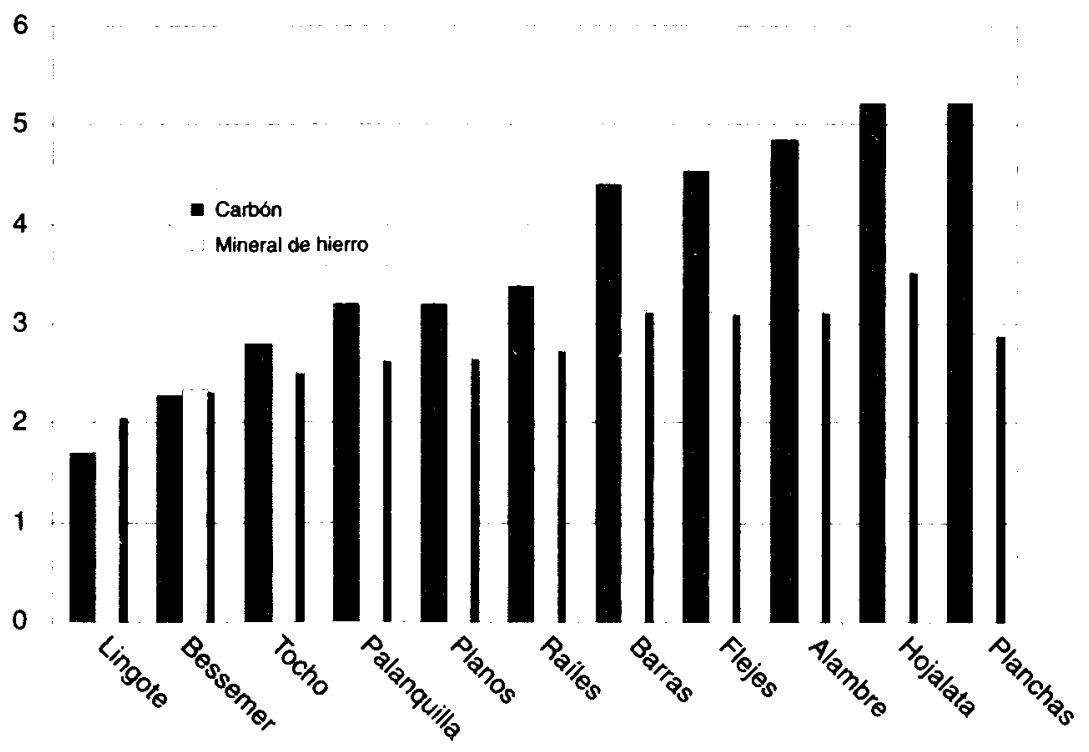

Fuente: Contabilidad de costes, Altos Hornos de Bilbao, vol. 1897 y Houpt (1998), vol. I, pp. 26-35.

rían en promedio menos de la mitad de los costes totales, y, en todo caso, una idea intuitiva ex ante sería que la suma de los gastos omitidos fuese mayor en España que en Gran Bretaña. Debemos partir del supuesto de que los mercados de factores no son competitivos. En el caso contrario, con funciones de producción idénticas, las retribuciones de estos factores serían idénticos.

Es decir, en un contexto de economía atrasada con mercados de factores menos integrados y poco competitivos, el capital en España se supone escaso y más caro y el trabajo más abundante pero proporcionalmente menos productivo. Con lo cual, los costes omitidos serían mayores en España que en Gran Bretaña. Si aceptáramos esta hipótesis, los gráficos ilustrarían la hipótesis sostenida por la historiografía española hasta ahora. En resumen, utilizando las mismas materias primas - mineral de hierro 


\section{GRÁFICO 4}

Gasto en mineral de bierro español y carbón británico para obtener una tonelada de lingote en 1897

(Chelines Gran Bretaña)

150

130

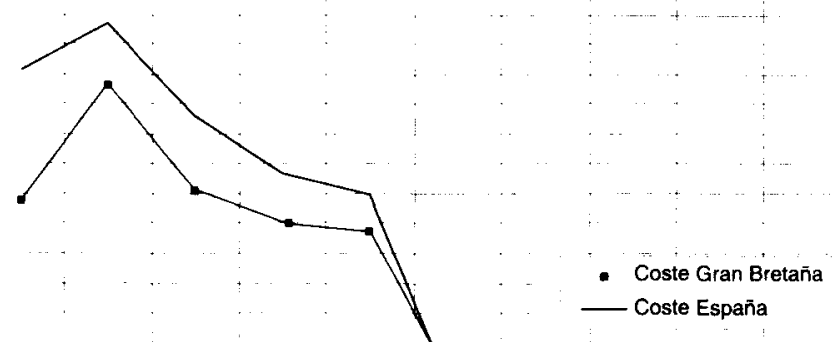

110

90

70

50

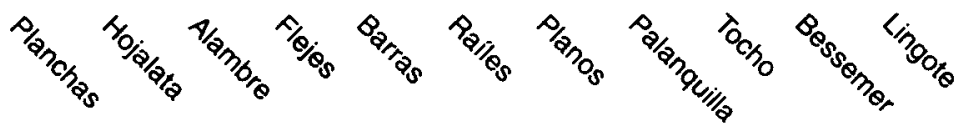

FUENTE: Véase gráfico 3.

español y carbón británico- España tenía una ventaja comparativa en la producción de productos intensivos en mineral de hierro: lingote de hierro, acero Bessemer, tocho de acero, palanquilla, planos y raíles. Por tanto, nos debemos fijar en estos productos para establecer si existía o no la posibilidad de competir en los mercadós internacionales.

El análisis de competitividad se llevará a cabo con datos de las fábricas de Altos Hornos de Vizcaya en Baracaldo y Sestao, por ser las más avanzadas técnicamente en la producción en masa de hierro y acero, por con- 


\section{TABLA 1}

Tabla de flujo productivo simplificado

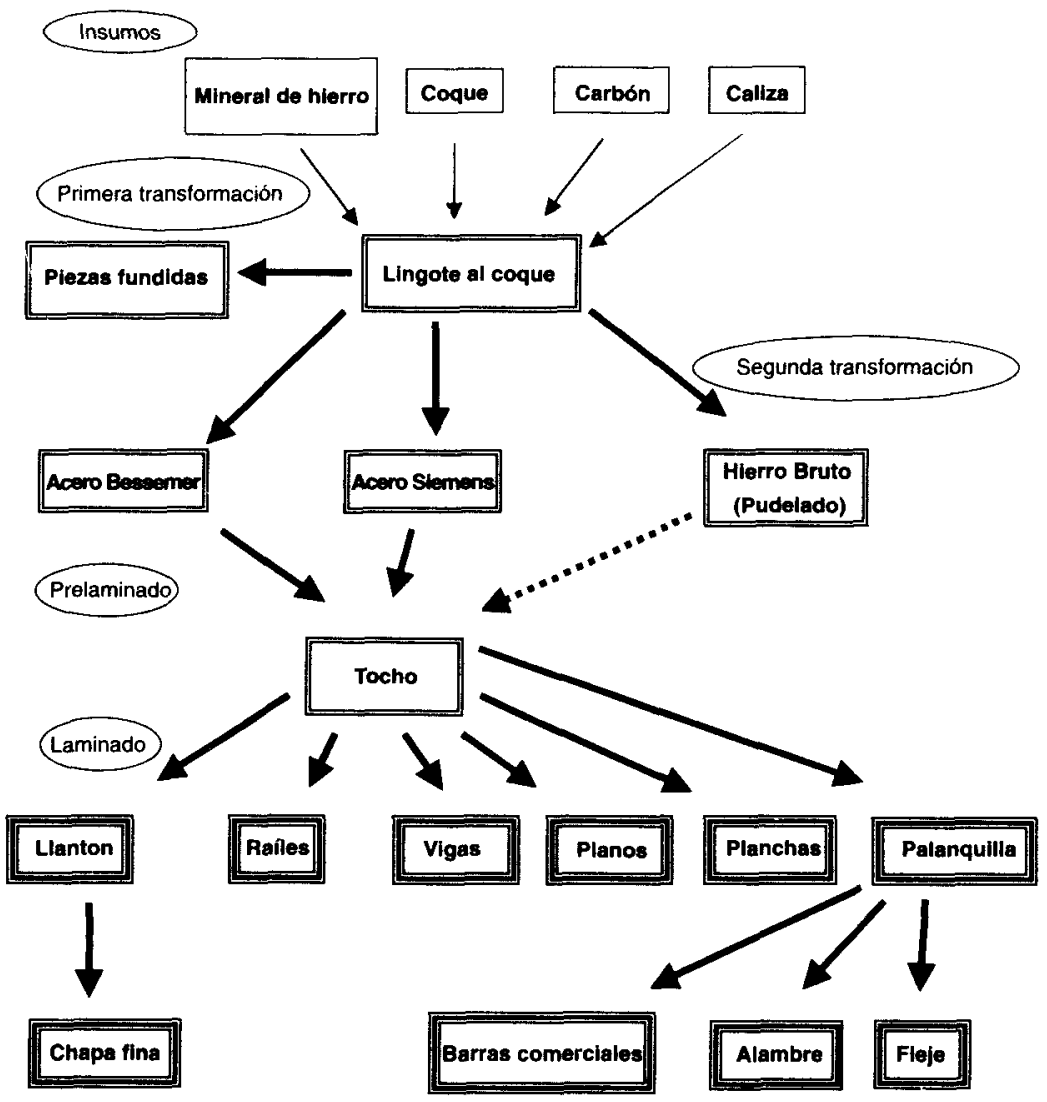

centrar cerca del 50 por 100 de la capacidad productiva en la mayor parte de las líneas de productos y por disponer de datos para poder someterlas a un examen exhaustivo. Los procesos productivos que en ellas se realizaron se pueden agrupar en tres fases sucesivas: la producción de lingote en hornos altos, el afino de acero en convertidores y hornos Siemens, y, por último, la transformación del acero en formas específicas en los talleres de laminación. El diagrama da una descripción más detallada de los procesos industriales implicados en dicha transformación. 


\section{EL AFINO DE HIERRO}

La primera fase de transformación, el afino de hierro, se analizará desde tres perspectivas. En primer lugar, definiremos lo que determinó el bajo coste inicial para las fábricas bilbaínas. A continuación, se hará un repaso de los problemas relacionados con el suministro de carbón y coque -el gran escollo para mejorar su competitividad-, y, finalmente, nos centraremos en los efectos que la innovación técnica introdujo en los departamentos de fundición para poder valorar estas inversiones.

La primera de las fábricas a analizar, la fábrica de Baracaldo, tiene sus orígenes en la Fábrica de Nuestra Señora del Carmen levantada por Ybarra y Cía. desde 1854. La fábrica original cubría una superficie de $64.000 \mathrm{~m}^{2}$, área que se incrementó sucesivamente por drenajes, llenados y adquisiciones de terrenos hasta llegar a los $116.500 \mathrm{~m}^{2}$ en 1896 . En 1882, los Ybarra canjearon todos sus activos por acciones de la recién creada Altos Hornos de Bilbao [AHB], empresa que se constituyó en los mismos terrenos de Baracaldo ${ }^{18}$. La creación de esta nueva compañía con capitales locales, catalanes, madrileños y franceses fue un paso necesario para financiar la modernización de la fábrica ${ }^{19}$. Esta modernización, bajo el régimen de sociedad anónima, fue planteada desde la década de los setenta por parte de los Ybarra para dar entrada a nuevos capitales, emitir obligaciones y reducir riesgo, todos ellos pasos necesarios para poder producir acero Bessemer ${ }^{20}$. El proyecto de modernización fue trazado y supervisado por $\mathrm{E}$. Windsor Richards, durante esos años director de Bolckow Vaughan, una de las más importantes empresas siderúrgicas británicas ${ }^{21}$. Con la reforma de la factoría se sustituyeron dos de los hornos antiguos con hornos altos al coque modernos, mientras que se mantuvieron dos de los hornos antiguos que empleaban mezclas o carbón vegetal. Estos

${ }^{18}$ Los activos traspasados por Ybarra y Cía. se valoraron en 5,6 millones de pesetas en 1884, esto incluía aparte de la fábrica de Baracaldo, por un lado, una fábrica de hierro más pequeña en Guriezo - Nuestra Señora de la Merced-, que a su vez fue vendida en 1899 por 159.771 pesetas, y, por otro, el traspaso de las cuotas de mineral de hierro que tenía contratadas Ybarra y Cía. con la Orconera Iron Co. Limited y la Société Anonyme Franco-Belge des Mines de Somorrostro de París, que serán analizadas más adelante. Sociedad Altos Hornos de Bilbao, Copiador de Escrituras (1882), pp. 276-303.

19 En realidad, según Diaz Morlán (1999), el 72 por 100 del capital nuevo aportado procedía del grupo Comillas-Crédiro Mobiliario.

20 Ybarra (2002), p. 671, y Díaz Morlán (1999), pp. 98-99.

$21 \mathrm{El}$ ingeniero Richards se mantuvo como asesor técnico de Altos Hornos de Bilbao. Visitó la fábrica, por ejemplo, en 1897 para inspeccionar los hotnos altos y revisar un proyecto de Siemens-Martin. 
hornos antiguos se reformarían en 1888 y 1891-1892, respectivamente. Los dos hornos modernos a base de coque dieron, inicialmente, a la fábrica una capacidad anual conjunta de $70.000 \mathrm{tm}$ de lingote de hierro para acero Bessemer. Después, con la reforma de los hornos antiguos la capacidad de lingote apto para el procedimiento Bessemer se incrementó hasta las $100.000 \mathrm{tm}$ al año.

Altos Hornos de Bilbao había «heredado» los dos contratos de suministro de mineral de hierro firmados por Ybarra y Cía. El primero, el contrato de mineral de Orconera que fue rubricado en 1873 , en virtud del cual la fábrica de Baracaldo recibiría $101.700 \mathrm{tm}$ de mineral de hierro al año a precio de coste, más un chelín y seis peniques por tonelada inglesa [1,88 pesetas por tm en 1873], fue cedido con una prima de 50 céntimos por tonelada ${ }^{22}$. Entre las condiciones del contrato destacaba que sólo podía revenderse el cupo en el caso de que alguna de las demás empresas vinculadas - Krupp, Dowlais, o Consett- lo hiciera anteriormente. El segundo contrato, que se había firmado en 1876 entre Ybarra y Cía. y la Société Anonyme Franco-Belge des Mines de Somorrostro, fue cedido también con una prima de 50 céntimos por tonelada ${ }^{23}$. En él se establece el suministro anual de hasta $50.000 \mathrm{tm}$ de mineral de hierro por el que se desembolsaría el precio de coste a pie de fábrica más 1,5 francos por tonelada [2,27 pesetas por tm en 1876]. La fábrica disponía libremente del mineral de la Franco-Belga y en numerosas ocasiones vendió su asignación anual. Ambos contratos tenían una duración de noventa y nueve años ${ }^{24}$. El contrato de la Orconera no contenía ninguna cláusula que permitiera, por parte de Ybarra Hermanos y Compañía, poner fin al arrendamiento de sus minas antes del término de contrato, es decir, a los noventa y nueve años desde la conclusión del ferrocarril [agosto de 1877] ${ }^{25}$. La importancia de estos contratos se percibe mejor con ayuda de la tabla 2 , en la que se compara la estructura de coste del lingote de varios centros de producción siderúrgicos en el mundo. Esta tabla ha sicio reproducida con

${ }^{22}$ Conocían bien el precio de coste, porque todas las empresas siderúrgicas que tenian contrato de suministro eran a su vez accionistas de la Orconera; ídem en el caso de la Franco Belga.

${ }^{23}$ Altos Hornos de Vizcaya (1902), pp. 67-76.

${ }^{24}$ Escritura de constitución de Altos Hornos de Bilbao, 1882.

${ }^{25}$ Solamente en caso de impago de renta o canon durante seis meses, con aviso y trascurridos otros tres meses para subsanar el impago tras el aviso, los Ybarra podrían volverse a apropiar de parte o todas sus minas y propiedades y se daría por terminado el arrendamiento. Orconera Iron Ore Limited (s. f.), pp. 37-38. El contrato de la Franco-Belga fue negociado en los mismos términos por José Antonio Ybarra Arregui. 
profusión en diversos trabajos sobre el sector ${ }^{26}$. En ningún caso se citan las fuentes últimas de los datos, pero destaca el posicionamiento extraordinario de Bilbao en esta comparación.

\section{TABLA 2}

Coste de factores en la producción de lingote y porcentaje del total (pesetas y porcentaje del coste total)

\begin{tabular}{lrrrrrr}
\hline $\begin{array}{c}\text { Min. bierm } \\
\text { ptas. (\%) }\end{array}$ & $\begin{array}{c}\text { Coque } \\
\text { ptas. (\%) }\end{array}$ & $\begin{array}{c}\text { Caliza } \\
\text { ptas. (\%) }\end{array}$ & $\begin{array}{c}\text { Trabajo } \\
\text { ptas. (\%) }\end{array}$ & $\begin{array}{c}\text { Otros ptas. (\%) } \\
\text { precio coste } \\
\text { pesetas }\end{array}$ \\
\hline Loire-F ................. $56,5(65,8)$ & $16,2(23,4)$ & $1,8(2,6)$ & $3,9(5,6)$ & $1,8(2,6)$ & 69,3 \\
Lieja - B ............... $38,4(60,4)$ & $17,4(27,4)$ & $1,8(2,8)$ & $4,2(6,6)$ & $1,8(2,8)$ & 63,9 \\
Westfalia - D.......... $38,4(61,2)$ & $16,8(26,8)$ & $1,8(2,9)$ & $3,8(5,7)$ & $2,1(3,3)$ & 62,7 \\
Cleveland - GB ....... $36,0(60,6)$ & $15,9(26,2)$ & $2,4(4,0)$ & $3,3(5,6)$ & $1,8(3,0)$ & 59,4 \\
Pittsburgh - EEUU... $31,8(70,7)$ & $7,2(16,0)$ & $1,8(4,0)$ & $3,0(6,7)$ & $1,2(2,7)$ & 45,0 \\
Bilbao - E............. $14,4(29,8)$ & $25,2(53,1)$ & $1,8(3,8)$ & $4,5(9,5)$ & $1,8(3,8)$ & 47,7 \\
\hline
\end{tabular}

FUENTE: Rodríguez Alonso (1902), p. 155.

La tabla muestra la importancia, en términos de costes, del mineral de hierro y del carbón en la constitución del precio final del lingote. La composición exacta de los costes de los factores de producción se determinó en gran medida por la cercanía de los inputs —de alto volumen y pesoa la fábrica. Las diferencias que se observan en la estructura de costes se atribuyen a que unos centros están localizados en cuencas carboníferas, mientras que otros se han localizado cerca del mineral de hierro, como es el caso de las factorías de Bilbao. En ambos casos observamos que es el factor de producción que se encuentra lejos de la fábrica, el que supone una parte importante del coste total. El gráfico 5 muestra los precios de mineral de hierro -Orconera y otros- para la factoría de Baracaldo, así como el precio de mineral de hierro en la plaza de Bilbao. El gráfico muestra una brecha importante entre los precios del mineral de hierro de la Orconera [la línea continua] y los precios de mercado [línea discontinua]. Esta brecha cubre el período de finales del $\mathrm{XIX}$ a los años veinte del siglo Xx. Para

${ }^{26}$ González Portilla (1981, p. 119) cita la Revista Minera, Metalúrgica y de Ingeniería, 1898 , p. 27 . Fernández de Pinedo (1987, p. 157) la recoge de la Revista Bilbao, 25 de diciembre de 1897, pp. 527-528 (sacado probablemente de la Iron and Coal Trades Review) y también Rodriguez Alonso (1902, p. 154) la obtiene de datos de una revista americana. 


\section{GRÁFICO 5}

Precios por tonelada de mineral de hierro, fábrica de Baracaldo y mercado (Chelines Gran Bretaña)

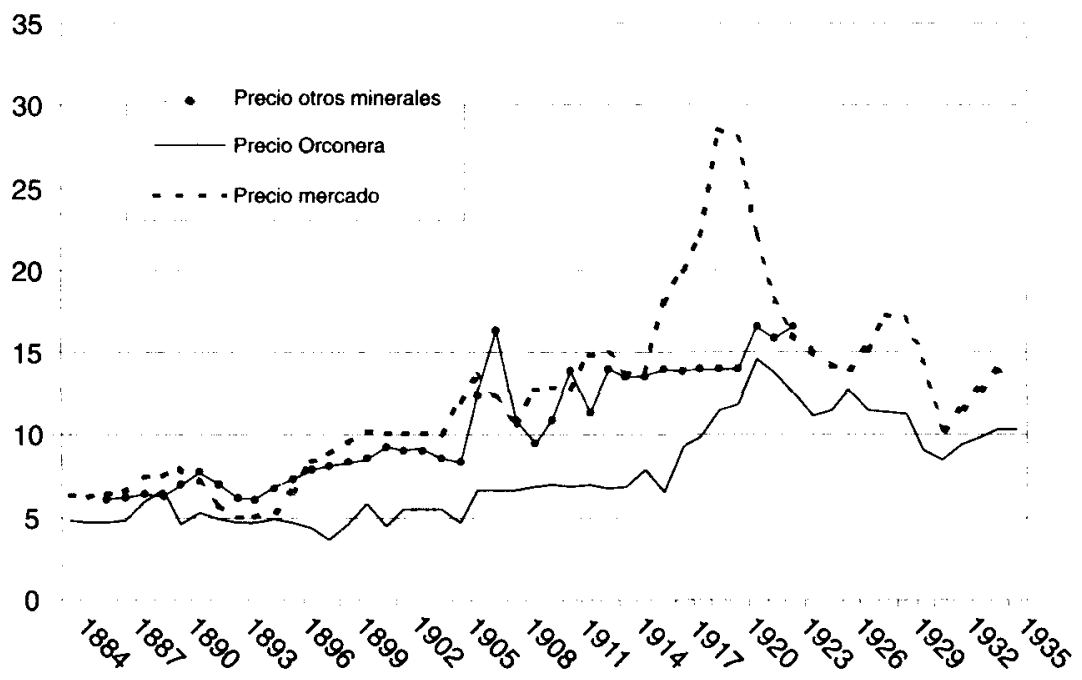

Fuente: Actas Consejo de Administración, Altos Hornos de Bilbao, La Vizcaya y Altos Hornos de Vizcaya, Escudero (1998), p. 339.

Nota: Otros minerales se refiere a otros minerales comprados por la fábrica de Baracaldo sin incluir el suministro fijo de la Orconera y de la Franco-Belga.

saber exactamente lo beneficiosos que fueron estos contratos para la Fábrica de Baracaldo podemos realizar el siguiente cálculo.

De 1897 a 1923, las $50.000 \mathrm{tm}$ de lingote de acero Bessemer, que se podían producir en Baracaldo partiendo de su cupo de $101.700 \mathrm{tm}$ de mineral de hierro de la Orconera, costaban de media 11,24 pesetas menos -el 68 por 100 menos - que cualquier tonelada de hierro adicional producida con mineral de hierro comprado a precio de mercado ${ }^{27}$. Por tanto, los precios preferenciales del mineral dieron un clara ventaja de costes para las primeras 50.000 toneladas de lingote; ventaja que desa-

${ }^{27}$ Todos los cálculos se efectuaron en pesetas reales. Los precios nominales se convirtieron en reales con el deflactor de la industria manufacturera de Prados de la Escosura (1995). El cálculo de beneficio se realizó con los minerales de la Orconera. Los minerales de la Franco-Belge se solían vender, dado que su composición no era muy apropiada para los hornos de Baracaldo. 
parecía de forma asintótica a medida que la fábrica de Baracaldo incrementaba la escala de producción más allá de las $50.000 \mathrm{tm}$ de lingote de acero Bessemer a las que limitaba el contrato Orconera.

De hecho, producir lingote de hierro para acero Bessemer a un precio de $€ 117 \mathrm{~s} 3 \mathrm{p}$ (60,7 pesetas) en 1897 (tal como se cita en la tabla 2) sólo era factible en Baracaldo con sus contratos preferenciales de suministro de mineral. Alcanzar este coste no era posible para las factorías que empleaban minerales comprados a precio de mercado. En resumen, los precios preferenciales de los minerales de hierro fueron la clave del bajo coste inicial del lingote, que a su vez, era la base de todas las transformaciones posteriores. En el caso de la fábrica de Baracaldo, esto era beneficioso mientras se produjese dentro de la escala marcada por el contrato con la Orconera.

Encontramos una pauta similar para la factoría de Sestao, que fue construida en un primer momento por La Vizcaya como fábrica de lingote ${ }^{28}$. Esta compañía fue creada por un grupo de capitalistas vizcaínos, propietarios de minas y comerciantes. El establecimiento fue proyectado y construido por ingenieros de la Société Anonyme John Cockerill de Bélgica, entre septiembre de 1882 y diciembre de 1885 . Los terrenos originales cubrían una superficie de $264.375 \mathrm{~m}^{2}$. Se componía en sus inicios de dos hornos altos al coque y sus aparatos auxiliares. Ambos hornos se encendieron en 1885, el primero a mediados de junio y el segundo en diciembre. Una vez terminadas las instalaciones de los hornos altos, los fundadores de la empresa consideraron de inmediato la expansión vertical hacia la producción de acero y productos laminados. Un tercer horno fue incluido en estos planes para hacer frente a la mayor demanda de lingote que resultaría de estas ampliaciones; el horno número 3 se encendió en 1891 y aumentó la capacidad anual de la fábrica hasta $120.000 \mathrm{tm}$ de lingote de hierro.

Casi de forma análoga a Altos Hornos de Bilbao, La Vizcaya arrendó en agosto de 1883 minas del distrito de Galdames para explotarlas hasta su agotamiento ${ }^{29}$. Los minerales de hierro se transportaban, según una cláusula incluida en el contrato de arrendamiento, a través de un ferrocarril

${ }^{28}$ La Sociedad de Metalurgia y Construcciones Vizcaya, La Vizcaya, fue una sociedad anónima constituida el 22 de septiembre de 1882. El proyecto original preveía una factoría integrada de transformación primaria y secundaria, pero en una primera fase la fábrica se concentró en la fabricación y venta de lingote para acero Bessemer. Véase Chávarri (1883).

${ }^{29}$ Galdames fue un distrito minero secundario al suroeste de Sestao, a unos $23 \mathrm{~km}$ de ferrocarril de la factoría. 
propiedad de la misma empresa, la Bilbao River and Cantabrian Railway Co. La calidad de los minerales de Galdames era inferior a la de los minerales de la Orconera y Franco-Belge, que extraían sus mineral del distrito minero de Triano, lo que creaba serios problemas en los hornos de La Vizcaya, tanto porque exigía un consumo muy alto de carbón como por la peor calidad de lingote que se obtenía. Por esta razón, a partir de 1886, los gerentes de la empresa acordaron emplear solamente el 50 por 100 del mineral de Galdames en la carga de los hornos. La cantidad restante se adquirió en el distrito de Triano y más tarde en el de Castro Urdiales ${ }^{30}$.

Con los pocos datos disponibles, hemos establecido una comparación del precio del mineral pagado por la fábrica de Sestao con los precios de la fábrica de Baracaldo y del mercado ${ }^{31}$. Los minerales de Galdames eran un 25 por 100 más caros que los de la Orconera, que utilizaba AHB y un 34 por 100 por debajo del precio del mercado. Por tanto, la fábrica de Sestao se beneficiaba, pero no tanto como la fábrica de Baracaldo, de poder utilizar mineral a un precio preferencial. Además, al contrario de esta última, su contrato con la empresa minera no ponía límites absolutos a la cantidad de mineral que podía utilizar cada año. Sin embargo, dicha cantidad se encontraba restringida por dos factores: las condiciones mínimas de laboreo que le exigía su contrato de Galdames y la composición de los minerales en su hornos. Para ambas fábricas hemos podido encontrar una relación directa entre la ventaja original en costes y los precios preferenciales de los minerales que empleaban. Pero en ambos casos, estas ventajas de costes se limitaban a una escala de producción determinada.

La segunda parte de nuestro análisis va a considerar el consumo de coque, el segundo coste material más importante en el proceso de afino del mineral de hierro. Desafortunadamente, la contabilidad mensual de las fábricas no incluye una serie desagregada continua del consumo de coque en sus hornos. Al examinar los datos agregados de los que disponemos, encontramos que el consumo promedio de coque por tonelada de lingote fue de unas 0,9 toneladas de coque por tonelada de lingote producida, para el período hasta la Primera Guerra Mundial. Como consecuencia de

${ }^{30}$ Durante la primera década del siglo xx el peso de los minerales de Galdames y Sopuerta aumentó de forma significativa por encima del 50 por 100 de la carga, quizás, como consecuencia de un mayor control en la homogeneidad de los minerales en origen y, por tanto, un aumento de su calidad. Aun así, hasta la Guerta Civil la cantidad extraída por la Factoría de Sestao nunca superó las 120.000 toneladas al año.

${ }^{31}$ Los datos de precios de mineral de Galdames y Sopuerta —el distrito colindanteson menos completos en las Actas del Consejo de Administración de La Vizcaya que en el caso de la Orconera en las de AHB. 
la guerra submarina, el consumo de los carbones nacionales en los hornos aumentó de forma importante durante el conflicto europeo. El uso de carbones nacionales incrementó el consumo unitario del coque hasta 1,3 toneladas (es decir, un 44 por 100 más). En otras palabras, la baja calidad de los carbones nacionales, muy inapropiados para el horno aito, disparó el consumo considerablemente. La ratio coque por tonelada de hierro producida cayó por debajo de 0,9 toneladas cuando se reiniciaron las compras de carbón al extranjero en los años veinte, y subieron de nuevo a 1,2 toneladas cuando los gerentes de la empresa optaron de nuevo por un uso mayor de carbones nacionales en los años treinta. Tanto la baja calidad de los carbones nacionales, como su elevado precio por unidad calórica, excluían la estrategia de sustitución del carbón importado por nacional como una táctica viable de reducción de costes.

Otra forma de reducir costes era la innovación tecnológica. Tanto la fábrica de Sestao como la de Baracaldo hicieron un gran esfuerzo en inversiones para aumentar la eficiencia de sus instalaciones. En 1889, como consecuencia de los aumentos abruptos de los precios internacionales de coque, Sestao efectuó una integración de la producción hacia atrás instalando hornos de coque Carvés con beneficio de subproductos. Esta factoría fue pionera en la adopción de los hornos de subproductos, que tanto en Europa como en Estados Unidos seguían en fase de maduración y experimentación. A mediados de los años noventa, la capacidad productiva de la fábrica se encontraba ya entre 154.000 y 160.000 toneladas de coque al año. Sus producción real nunca alcanzó estos niveles y esta infrautilización de sus instalaciones impedía alcanzar las economías de la escala óptimas de producción ${ }^{32}$.

Durante una segunda escalada de precios de coque, entre 1898 y 1901, y siguiendo el ejemplo de Sestao, también se construyeron 3 baterías de 25 hornos de coque Semet-Solvay en Baracaldo, con una capacidad de 90.000 a 100.000 toneladas por año. Una cuarta y quinta batería Carvés modificadas se añadieron en 1907 y 1911, respectivamente, aumentando su capacidad total a $150.000 \mathrm{tm}$. Las instalaciones de coque de Baracaldo se empleaban con mayor intensidad. La fábrica llegó a producir 87.000 toneladas al año ( $\approx 90$ por 100 de su capacidad productiva) en un corto

32 Por ejemplo, se alcanzó un 80 por 100 de capacidad en diciembre de 1896. El coque se empleaba casi exclusivamente en la producción de lingote, donde hemos visto que menos de una tonelada era necesaria para afinar dos toneladas de mineral y obtener una tonelada de lingote. La producción de lingote determinaba el volumen de coque necesario. 
período de competencia libre de mercado, entre 1905 y 1906, y su promedio de producción se mantuvo alrededor de las 135.000 toneladas (90 por 100) entre 1913 y 1916. En ambas fábricas, la integración hacia atrás redujo los costes unitarios del coque, porque el precio de los carbones extranjeros que se prestaban a la coquización era ligeramente más bajo que el precio de la cantidad de coque equivalente obtenido, comprado en los mercados internacionales.

Se podía haber obtenido un ahorro importante mezclando los carbones británicos y galeses con otros más baratos. Las técnicas y conocimientos disponibles permitían la mezcla de carbones para poder emplear incluso pequeñas cantidades del mejor carbón español. Pero la mala calidad del carbón español y el alto coste de transporte de otros sustitutos europeos limitaron dicha estrategia. A pesar de sus limitaciones, se observa cómo, en el cambio de siglo, el carbón de coque llegaba a Bilbao desde León por ferrocarril y, desde Asturias, por mar y tierra. Pero los efectos nocivos del coque español sobre los recubrimientos de los hornos y las impurezas que introdujo en el lingote limitaron su uso por debajo del 20 por 100 hasta la Primera Guerra Mundial. Eran más baratos, pero de peor calidad, y su uso en pequeñas cantidades permitió a las fábricas reducir ligeramente los costes sin un perjuicio demasiado grave en la calidad del producto ${ }^{33}$.

Otro elemento técnico que experimentó importantes cambios a nivel mundial fue el diseño del horno alto. Se trataba de calibrar la altura y forma de los hornos para optimizar el uso del calor, la velocidad de reducción del mineral en función del mineral y el carbón empleado. En el caso de las fábricas que estamos examinando, el perfil de los hornos se alteró muy ligeramente. La altura de los hornos aumentó en más de un metro en Baracaldo, y en Sestao su volumen se incrementó en un 9 por 100, transformándolos de achatados a forma de punta de lanza ${ }^{34}$. Paralelamente, la producción de los hornos se dobló entre 1900 y 1924, pasando de 100 a 200 toneladas diarias. No fueron las variaciones del perfil de los hornos las principales causantes de estos notables incrementos de la producción, sino los aumentos de la presión a la que se inyectaba el aire caliente por las toberas del horno. El soplado forzado aumentaba sustancialmente la velocidad de marcha del horno. Por ello, las principales inversiones del

${ }^{33}$ La cuestión de la sustitución de carbones ha sido estudiado más exhaustivamente en Fraile (1982) y resumido con más detalle que aquí en Houpt (1998), vol. I, pp. 15.20.

${ }^{34}$ González Portilla (1985a), p. 89. La Vizcaya, Actas del Consejo de Administración, vol. II, p. 305. 
departamento de hornos altos de Sestao y Baracaldo eran gastos en estufas y turbo-soplantes ${ }^{35}$. Estos equipos aumentaban la presión del aire caliente, permitiendo, simultáneamente, mantener una temperatura muy elevada del aire, una práctica conocida como «marcha forzada». La marcha acelerada del horno, conseguida por la mayor presión del aire inyectado, aumentó la producción de los hornos, pero al mismo tiempo deterioró más deprisa los recubrimientos ${ }^{36}$.

En el caso de Baracaldo, la primera oleada de inversiones encaminadas a aumentar la presión del aire inyectado se produjo entre 1902 y 1903 y coincide con una caída del precio de coste del lingote desde 47 a 40 chelines. En una segunda fase, de 1911 a 1913, se instalaron nuevas estufas Koper, aunque con menos éxito, ya que se observa cómo los precios de coste de la tonelada de lingote aumentaban gradualmente hasta alcanzar el coste anterior a 1902. Teniendo en cuenta que los precios del carbón, tanto de los nacionales como de los extranjeros, bajaban después de 1911, y que los precios del mineral de hierro fluctuaban hasta la Primera Guerra Mundial pero se mantenían por debajo del nivel de 1911, la única explicación para esta subida se encuentra en el hecho de que dos de los hornos, el número 1 y el número 3 , llevaban entre cinco y seis años de uso continuado y necesitaban una renovación de recubrimiento. No podemos separar el efecto que tuvieron las nuevas estufas.

Durante la contienda europea, llama la atención que los precios del lingote se mantuvieran relativamente estables. El precio real del mineral había caído un 40 por 100 hasta 1918 y los precios del carbón se habían triplicado, para después situarse en un 200 por 100 de su nivel anterior de la guerra. Los tres hornos que continuaban la marcha durante la guerra habían sido renovados en 1912, 1913 y 1917 respectivamente y sus soplantes habían sido modernizadas recientemente. No sabemos a ciencia cierta si la bajada en el precio del mineral, o los cambios técnicos, o ambos, mantuvieron los precios de coste tan bajos, mientras que el precio del carbón aumentó significativamente. Pero lo que sí observamos, es que los precios de coste del lingote nunca volvieron a bajar a los niveles anteriores a la guerra, aunque tanto el carbón como el mineral de hierro establecieran

${ }^{35}$ Con una única excepción en el caso de Baracaldo, donde se instaló la carga mecánica del horno en 1926.

${ }^{36}$ Se observa la reducción de los intervalos de renovación de los recubrimientos de los hornos. Entre 1897 y la Primera Guerra Mundial, éstos se redujeron de 9 a 4 años en Baracaldo, y de 11 a 4 años en Sestao. Véase Houpt (1998), vol. I, capítulo segundo para una discusión, más exhaustiva de la marcha forzada. 
precios cercanos a sus niveles prebélicos. Las ocho pesetas en las que aumentó el coste unitario del trabajo, no explican por qué los precios de coste del lingote subieron de 60 a más de 200 pesetas por tonelada. Seguramente, la variable desconocida, el consumo de coque, revelaría el porqué. El consumo de coques nacionales en Altos Hornos de Vizcaya aumentó de un 30 por 100 de la carga a más del 90 por 100 entre 1918 y 1920. La sustitución de los coques extranjeros por nacionales aumentó el consumo de carbón y redujo la marcha productiva de los hornos de forma sustancial.

En el departamento de hornos altos de Sestao también se realizaron inversiones importantes, primero en 1906 y más tarde en 1913. Ambas modernizaciones incluían la renovación de soplantes. El precio de coste de producción del lingote cayó entre 1901 y 1906 de 47 a 39 chelines y mantuvo este nivel hasta 1911. Paralelamente, Sestao experimentó cambios en su producción, pasó de producir 100.000 toneladas de lingote/año en la última década del siglo XIX a producir 65.000 tm/año en 1902, para ir subiendo paulatinamente hasta un nivel de $90.000 \mathrm{tm} /$ año en la segunda década del siglo $\mathrm{xx}$ y caer a $40.000 \mathrm{tm} /$ año en los años veinte. El precio de coste de su lingote fue subiendo lentamente entre 1911 y 1917, se disparó hasta 1919 para situarse en el doble de su nivel de antes de la guerra en los años veinte. Los movimientos en el coste del lingote de Sestao reflejan más bien las fluctuaciones en su escala de producción que el efecto de la renovación de sus soplantes. Al igual que el caso de AHB, durante la Primera Guerra Mundial el mayor consumo de carbones nacionales afectaba tanto al rendimiento como al coste de lingote de la fábrica de Sestao.

Hemos visto que la ventaja original del coste del lingote de hierro, tanto para Baracaldo como Sestao, se basaba sobre todo en contratos preferenciales de mineral, que a su vez limitaban fuertemente la escala de producción para poder obtener esta ventaja de precio. La sustitución del carbón inglés y galés era difícil dados los altos costes de transporte para sustitutos extranjeros y la mala calidad de los carbones nacionales. Hemos observado, en los últimos años de la Primera Guerra Mundial, cómo pequeños porcentajes de carbón español podían mezclarse con los carbones extranjeros, pero estas pequeñas fracciones bajaban el rendimiento sustancialmente. Queda descartada, por tanto, la posibilidad de haber mejorado la competitividad del lingote español a través del consumo de carbones nacionales. Ambas fábricas introdujeron cambios en sus equipos. En ambos casos, las innovaciones iban dirigidas principalmente a aumentar la presión del aire que se inyectaba en el horno alto para acelerar la marcha del 
horno. El aumento en el rendimiento de sus hornos puede considerarse bastante moderado; frente a las $200 \mathrm{tm} /$ día producidas hacia 1920, hornos de dimensiones parecidas llegaban a producir una media de 500 toneladas al día en otros lugares del mundo ${ }^{37}$. El margen reducido en la producción de lingote nos obliga a investigar otras áreas de producción en búsqueda de estrategias que mejorarian la competitividad de los productos vizcaínos.

\section{LOS CONVERTIDORES DE ACERO}

En el caso de Baracaldo, los dos nuevos hornos altos se construyeron para alimentar una planta de acero Bessemer de diseño estadounidense con dos convertidores de 10 toneladas ${ }^{38}$. El precio de la planta en 1884 era de 41.455 libras esterlinas, por encima del coste de establecimientos europeos equivalentes ${ }^{39}$. E. Windsor Richards, el ingeniero británico que diseñó la reforma de Baracaldo, era poco partidario de la organización laboral estadounidense, porque el control de calidad del producto se hacía más difícil ${ }^{40}$. Los americanos trabajaban sus convertidores en tres turnos de 8 horas, optimizando el número de lotes realizados en 24 horas y minimizando errores, accidentes y negligencias que se atribuían a la fatiga. Los altos costes laborales y el rápido deterioro de los recubrimientos se compensaban con la mayor producción ${ }^{41}$. En Alemania, en una planta

${ }^{37}$ Apraiz (1978), p. 263.

${ }^{38}$ Los convertidores se encontraban en una plataforma, los dos orientados de frente para verter el acero acabado al suelo, lo que facilitaba su rápida colada por grúas secundarias y su retirada por ferrocarriles que cruzaban la planta. Esta disposición en plataforma también facilitaba las tareas de reparación y mantenimiento. Empleaban el procedimiento directo que consistía en procesar lingote líquido traído de los hornos altos.

${ }^{39}$ Para Baracaldo: Actas del Consejo de Administración, Altos Hornos de Bilbao, vol. I, pp. 104-105. Thomas y Gilchrist (1882, p. 375) estimaban el coste de una planta de las mismas características en Gran Bretaña, entre 24.000 y 26.000 libras en 1882; la Glasgow Iron Co. construyó una planta con tres convertidores de 7 toneladas - capacidad total de 21 toneladas - , unas instalaciones para fabricar calderas y un taller de palanquilla por 30.000 libras en 1883; Phönix se gastó 40.000 libras en una planta con tres convertidores de 10 toneladas a principios de los ochenta del siglo xxx. Wengenroth (1993), p. 175. Las comparaciones se hicieron con tres plantas de proceso básico, Baracaldo construyó una planta de proceso ácido. Técnicamente son idénticos, la diferencia descansa en los minerales que procesan, el recubrimiento de los convercidores y el fundente que se emplea en ellos.

${ }^{40}$ «He [Richards] felt that the biggest impediment was that with such hurried work which we term "driving", we could not fulfil the conditions of the exacting specifications of English and Continental Engineers, and so requiring more time, we are obliged to do the same amount of work with more converters and labor force.m Wengenroth (1993), p. 145, citando a E. W. Richards en Iron and Coal Trade Review, 27 de enero de 1882, p. 101.

${ }^{41}$ Para descripciones más detalladas, véase Nuwer (1988) o Wengenroth (1993), capítulo 2 . 
de dos convertidores que empleaban las técnicas americanas en la década de 1880, era común obtener más de 34 lotes en 24 horas ${ }^{42}$. Para la fábrica de Baracaldo, Alzola registró un promedio de 16 cargas en jornadas laborales de 12 horas en 1895, lo cual representa, en teoría, 32 cargas en 24 horas $^{43}$. A este ritmo, la planta de Baracaldo podría haber producido $91.500 \mathrm{tm}$ de acero Bessemer. Tardaron hasta 1906 — veinte años más tarde- en alcanzar esta producción ${ }^{44}$. El número promedio de cargas en 24 horas, en 1906, empleando los convertidores de 10 toneladas, fueron 35. El potencial de acelerar y coordinar el proceso productivo fue mucho mayor, como refleja el número máximo de cargas por día que se obtuvo con 57 cargas en 1913, un año antes de aumentar la capacidad de los convertidores de 10 a 15 toneladas.

La pauta organizativa en la producción Bessemer, en el resto del mundo, era aplicar técnicas de flujo continuo para mantener el ritmo alto de la «marcha forzada» de los hornos altos. Este proceso implicaba el uso de las mismas instalaciones y personal, pero de una forma intensa, con el fin de incrementar el flujo de producción. Wengenroth calculó que con una duplicación de los costes de capital, la capacidad de producción de los convertidores se multiplicó por cinco entre la década de 1860 y la de $1880^{45}$. Esto redujo significativamente el coste unitario del acero. El gráfico 6 muestra las cargas medias en las fábricas de Baracaldo y Sestao entre 1897 y 1922. El incremento gradual muestra que hubo un margen sustancial para acelerar las operaciones de afino hasta el inicio de la Primera Guerra Mundial.

Los datos de ventas de productos finales de acero son los únicos indicadores de la producción de acero de los que disponemos antes de 1897. El promedio anual de productos de acero y hierro pudelado vendido en Baracaldo fue de $42.187 \mathrm{tm}$, con un máximo de $47.783 \mathrm{tm}$ en $1890^{46}$. Teniendo en cuenta que el 25 por 100 de estos productos era de hierro pudelado, llegamos a la conclusión de que los gerentes estimaban que el uso de los

${ }^{42} \mathrm{El}$ número de cargas por día = [producción mensual]/([días trabajados este mes] $\times$ [capacidad]). Hay que tener en cuenta que se define aquí la capacidad de los convertidores Bessemer como la que obtiene al estar funcionando simultáneamente: en este caso un convertidor sopla, mientras el otro se vierte, recarga, etc. Los cálculos siguen el método propuesto por Wengenroth (1993, pp. 54-55).

${ }^{43}$ Alzola (1896), p. 32. No es del todo sostenible, dado que la marcha continua de los convertidores implica vidas útiles distintas para los recubrimientos y tiempos muertos mayores, pero 32 cargas puede servir como punto de referencia.

4434 cargas $\times 10 \mathrm{tm} \times 5,5$ días laborables $\times 50$ semanas $=91.500 \mathrm{tm}$.

45 Wengenroth (1986), p. 88.

46 Memorias de Altos Hornos de Bilbao y González Portilla (1985a), p. 166. 


\section{GRÁFICO 6 \\ Promedio de cargas realizadas en $24 \mathrm{~b}$. en los departamentos de convertidores de $A H V$ \\ (Número de cargas)}

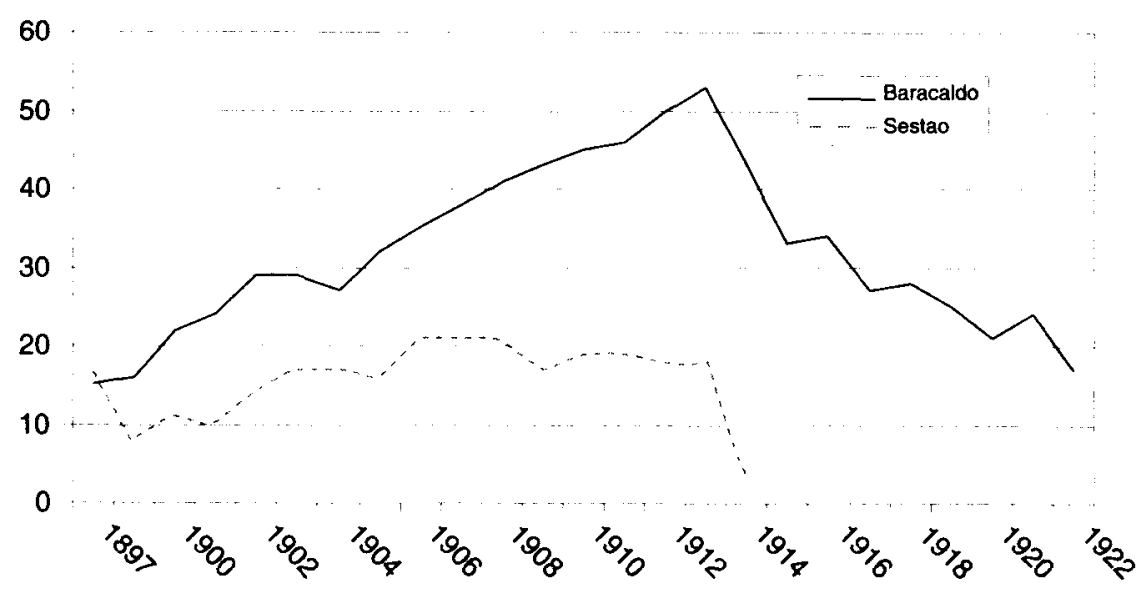

FuENTE: Houpt (1998), p. 86.

convertidores a una marcha «alemana», pero durante tan sólo doce horas al día, era más que suficiente. Trabajar día y noche era factible desde el principio. En los talleres de laminado se introdujo el alumbrado eléctrico en septiembre de 1886, pero en los talleres Bessemer los turnos de noche no se introdujeron hasta abril de $1900^{47}$. En cambio, para 1905-1906, en un período de competencia de libre mercado, las operaciones habían alcanzado la plena capacidad de las instalaciones ${ }^{48}$. Mientras tanto, entre 1886 y 1905 , los gerentes habían explotado la planta Bessemer a media jornada.

Los únicos cambios técnicos que cabe resaltar en los talleres de Bessemer fueron las reformas de 1913-1914. Dos nuevos convertidores de 15 toneladas sustituyeron a los anteriores de 10 toneladas, una soplante de $2.300 \mathrm{CV}$ a gas sustituyó a las dos Galloways anteriores de $600 \mathrm{CV}$,

${ }^{47}$ Actas del Consejo de Administración, Altos Hornos de Bilbao, sesiones de 18 de septiembre de 1886 y 26 de abril de 1900.

${ }^{48}$ Desde la última década del siglo XIX el sector siderúrgico español estaba fuertemente cartelizado. Entre 1905 y 1906 experiınentó un episodio de libre competencia para eliminar una planta malagueña que vendía por debajo de los precios de colusión. 
se introdujo una moderna grúa Stripper para el deslingote y se aumentó la superficie de taller para dar mayor capacidad de maniobra. Pero los costes unitarios del acero Bessemer cayeron sobre todo por el aumento de la producción. Hasta 1910-1911, a medida que se triplicaba la producción, los precios mantuvieron una tendencia a la baja. Observamos caídas en los costes unitarios de trabajo. Por otro lado, el coste dominante es el de la materia prima: el lingote. Pero la tendencia a la baja del precio de coste del acero Bessemer era mucho más importante que la del lingote y podemos comprobar que se redujo más de lo que puede atribuirse a la bajada del coste del lingote. Fue el uso eficiente de los equipos, combinado con pequeñas inversiones en equipos auxiliares, el que incrementó la velocidad de colar el acero, aumentó la velocidad de los procesos y redujo de manera relevante los costes unitarios.

Es importante, llegados a este punto, subrayar las oportunidades perdidas. Dado que los convertidores Bessemer se comercializaban e instalaban en toda Europa por la empresa Galloway, la misma inversión que se realizaba en Alemania, Bélgica o Gran Bretaña daba en España un rendimiento muy inferior. Los equipos españoles, idénticos a los de sus homólogos, producían la mitad de acero. Esta ineficiencia se transmitió a los sucesivos procesos de transformación, dado que el acero Bessemer se empleaba para la mayoría de los productos intermedios y finales. Los costes unitarios altos del acero se transmitieron, de esta forma, a otras líneas de productos, aumentando sus precios de coste. El aumento de capacidad de los convertidores $(+50$ por 100$)$, que se introdujo poco antes de la Primera Guerra Mundial, había restablecido el exceso de capacidad y bajado el número de cargas por día de forma considerable ( -37 por 100). La intensidad de uso de los convertidores caía de 53 cargas en 1913 a 33 cargas en 1915 , momento en el que ambos convertidores nuevos estaban en funcionamiento. A su vez, el coste medio de una tonelada de acero Bessemer pasó de 87 pesetas en 1912 a 101 pesetas en 1915. Los equipos volvían a operar de forma subóptima.

El taller de Bessemer de Baracaldo se complementó en 1887 con un horno de acero Siemens-Martin ácido de 10 toneladas, para la fabricación de planchas de acero para la construcción naval, y otro horno básico de 15 toneladas en 1898. La capacidad anual de hornos de este tamaño, en el cambio del siglo, era de unas 21.000 toneladas métricas al año, afinando tres cargas diarias ${ }^{49}$. En 1897, Alzola especifica que el horno de 10 tone-

${ }^{49}[3$ cargas $] \times[25 \mathrm{t}] \times[5,5$ días laborales $] \times[50$ semanas $]=20.625 \mathrm{tm}$ o $[3$ cargas $] \times[25 \mathrm{t}] \times[23,91$ promedio de días laborables al mes $)] \times[12$ meses $]=21.520 \mathrm{tm}$. 
ladas producía hasta 11 toneladas por carga y 18 cargas a la semana. Realizando cálculos con estas cifras nos darían aproximadamente 2,6 cargas al día. Aunque no disponemos de datos desagregados para la producción Siemens antes de 1897, el total de productos finales nos indica que los gerentes no empleaban los hornos a este ritmo.

El precio proyectado del primer horno de acero Siemens fue de 7.843 libras esterlinas en noviembre de 1884; esto se situaba bastante por encima de las 5.000 libras que pagó Consett para unas instalaciones comparables en 1879 o las 4.000 libras por horno que pagaron en $1886^{50}$. Teniendo en cuenta que los hornos de acero Siemens eran estrictamente comparables en este periodo, ya que experimentaron pocas variaciones técnicas, los costes de ambos hornos eran bastante superiores ( +96 por 100) a los construidos en Gran Bretaña. El horno básico de $15 \mathrm{tm}$ costó alrededor de 8.600 libras en 1898 y resultó más económico que el primer horno, pero seguía costando más que el de Consett $(+43$ por 100 en términos de capacidad instalada). Hasta principios de los años treinta, cuando instaló 3 hornos Siemens-Maerz nuevos de 60 toneladas, Baracaldo no invirtió ninguna cifra relevante en sus instalaciones Siemens. A pesar de ello, hasta 1906 los precios de coste cayeron, muy probablemente por el aumento de producción y porque, como revelan los libros de contabilidad de costes de la empresa, los costes del lingote de hierro caían.

El proyecto original de la fábrica de Sestao preveía una producción de 100.000 toneladas anuales de lingote, que serían convertidos en acero por medio de convertidores Bessemer. A su vez, el acero resultante se transformaría en productos finales en un taller de laminación colindante. Una segunda fase de inversión añadiría otros cuatro hornos altos más para alimentar un tren de planchas para la construcción naval y una fundición. Un contratiempo serio para este proyecto fue la adquisición de los derechos de patente para el procedimiento Bessemer por parte de su empresa competidora, Altos Hornos de Bilbao, lo que imposibilitó los planes originales ${ }^{51}$.

El concurso de aceros nacionales para la construcción de buques militares por parte de la Marina y la adjudicación de un proyecto importante de construcción naval militar a una empresa de la Ría de Bilbao - Astilleros del Nervión- impulsó a los fundadores de Sestao a adoptar hornos de acero Siemens-Martin. Construyeron tres hornos con una capacidad entre 10 y 12 toneladas en 1889 y añadieron un cuarto horno en 1890 . Haciendo

\footnotetext{
so Wengenroth (1993), p. 200.

"1 Chávarri (1883) y González Portilla (1985a), pp. 63-64.
} 
una comparación de costes, al igual que hicimos en el caso de Baracaldo, el precio medio de los hornos era de 7.400 libras esterlinas, un poco menos de lo que había pagado Baracaldo, pero todavía bastante por encima de lo que desembolsó Consett -unas 4.000 libras por horno en 1886 . Al alto coste de los hornos le podemos sumar la infrautilización de las instalaciones, 1,36 cargas diarias entre 1890 y 1895 y 2 cargas diarias entre 1896 y 1901 . La capacidad teórica de las instalaciones era de 34.000 toneladas al año, aunque lo más que sus gestores se acercaron a esta cifra fue en 1898, con una producción de 24,766 toneladas anuales —el 73 por 100 de su capacidad teórica ${ }^{52}$. El promedio de cargas en el período anterior a la Primera Guerra Mundial fue de 1,9. Eran factible alcanzar mayores niveles de producción, como demuestran los altos promedios -2,3 cargas diarias- que se alcanzaron entre 1905 y 1906, con la libre competencia de las empresas siderúrgicas españolas.

En 1909, se añadieron dos hornos Siemens de 20 toneladas y poco a poco este tamaño iba sustituyendo a los anteriores. En 1919, la fábrica ya disponía de 10 hornos de acero Siemens de 20 tm que realizaban 1,4 cargas promedias al día. Hacia finales del siglo $\mathrm{xxx}$, los hornos de acero de Sestao tenían todos recubrimientos básicos, pero esto no les proporcionaba ninguna reducción importante en el coste unitario, aunque les permitió procesar una cantidad mayor de carbonatos que abundaban con el agotamiento de los minerales de gran pureza. Aun así, el coste del mineral se mantuvo igual o incluso aumentó ligeramente ${ }^{53}$. La gran alternativa al mineral, la chatarra, podía haber abaratado el coste final, pero era una materia prima escasa en España. Los precios del acero Siemens de Sestao cayeron hasta 1906. Los cambios en las instalaciones no explican estas reducciones. Por otro lado, el precio del carbón disminuyó ligeramente en este período y puede dar alguna explicación. Pero a grandes rasgos, los precios de coste del acero Siemens seguían los mismos ciclos que el precio de coste del lingote, la fuente principal de la reducción de su coste.

Para el procesamiento de hierro en acero de calidad Bessemer, La Vizcaya se vio obligada a instalar convertidores Robert, similares a los Bessemer pero cuya patente estaba en manos de Altos Hornos de Bilbao. Tres convertidores Robert de toberas laterales se instalaron en 1891 con una capacidad marcadamente inferior a los Bessemer de Baracaldo - 2,5 toneladas de capacidad cada uno-. A lo largo del mismo año se aumentó

$52[3$ cargas $] \times[40 \mathrm{t}] \times[5,5$ días laborales $] \times[50$ semanas $]=33.000 \mathrm{tm}$ o $[3 \mathrm{car}$ gas $] \times[40 \mathrm{t}] \times[23,91=$ (número promedio de días laborables al mes) $] \times 12=21.520 \mathrm{tm}$.

${ }^{3}$ Véase Escudero (1998), pp. 339-340. 
su capacidad a 4,5 toneladas y se añadieron dos convertidores más. La mayor dotación de aparatos les permitía soplar dos convertidores a la vez, mientras otros dos colaban y el quinto convertidor estaba en reserva. Esto hace las instalaciones comparables a una planta Bessemer de dos convertidores de 9 toneladas. Volviendo al gráfico 6, vemos el bajo rendimiento que prestaron los convertidores de Sestao en comparación con la planta Bessemer de Baracaldo. Calculando a partir de las cifras de producción anuales entre 1892 y 1896, sus cargas diarias se situaban entre 5 y 6 al día. Sus convertidores eran significativamente más pequeños que los Bessemer y sus equipos auxiliares menos sofisticados. Esto explica en parte su bajo rendimiento y su desmantelamiento en el seno de Altos Hornos de Vizcaya en 1914, una vez llevada a cabo en Baracaldo la sustitución de los convertidores Bessemer de $10 \mathrm{tm}$ por otros de $15 \mathrm{tm}$.

En 1899, los convertidores Robert se transformaron en Tropenas y su producción había aumentado de 1.500 toneladas al mes hasta 2.500 en 1905. Pero posteriormente bajó de nuevo a 2.000 toneladas hasta su desmantelamiento definitivo en 1914. Sus precios de coste nunca se situaron por debajo de las 100 pesetas por tonelada, frente a unas 80 pesetas de coste unitario del acero Bessemer en Baracaldo. Entre los demás cambios que sufrieron las fábricas en la transformación de acero, caben destacar la adopción de un mezclador y la supresión del pudelado. La instalación del mezclador de 250 toneladas en la fábrica de Baracaldo agilizó el flujo de la transformación primaria a la secundaria a partir de 1904. Estos recipientes transitorios se empleaban en las empresas siderúrgicas más modernas de Gran Bretaña desde 1890. Este primer mezclador se sustituyó en 1928 por otro de 600 toneladas en una versión reductora de azufre, que se usaba en Estados Unidos y Europa desde finales del siglo XIX. Los mezcladores servían para homogenizar y ajustar de forma más exacta la composición química del lingote líquido-fundamental para la marcha de los convertidores. Por otro lado, ambas factorías tenían desde sus inicios instalaciones de pudelaje, 14 hornos en Baracaldo y 4 en Sestao. Éstos desaparecieron definitivamente en 1907-1908.

Referente a la transformación de acero a través de convertidores, podemos concluir que el proceso Bessemer en Baracaldo alcanzó plena capacidad tardíamente - veinte años después de encenderse- y que estas instalaciones se podían haber utilizado de una forma mucho más intensa y eficiente. El hecho de que los convertidores Robert y posteriormente Tropenas se mantuvieran en Sestao hasta 1914, veinticinco años después de que dejaran de estar vigentes los derechos de la patente Bessemer, y que 
los turnos de noche no se introdujeran en Baracaldo hasta 1900 , muestra que ninguna de las dos fábricas respondía a los principios de minimización de costes unitarios vía aumento de economías de flujo.

Los hornos Siemens eran una técnica menos susceptible a las economías de flujo, ya que sus costes de capital variaban casi proporcionalmente con el tamaño de los hornos y sus costes variables proporcionalmente con la cantidad que producian. El acero Siemens se producía en lotes con tiempos largos de transformación, unas ocho horas, y el aumento en su capacidad se obtenía de forma extensiva - añadiendo unidades de producción del mismo tamaño-, y no de forma intensiva - aumentando la producción individual de los hornos. Una externalidad importante para la competitividad de los hornos Siemens de Bilbao era el hecho de que el acero Siemens básico se iba imponiendo por encima de los demás tipos de acero - acero Bessemer, acero Thomas y acero Siemens ácido- en el transcurso del siglo xx. El acero Siemens básico era un acero producido a partir de lingote básico y mineral de hierro, o partiendo de una combinación de chatarra, lingote básico y mineral de hierro —en este orden de importancia-. Su predominio creciente en los mercados europeos y americanos en este período se puede atribuir a los precios más bajos de sus materias primas, al coste ligeramente inferior de procesamiento y a la mayor calidad de acero que proporcionaba. La industria del acero bilbaína se basaba en el lingote ácido y, dado el atraso relativo de España en la industrialización, la chatarra no era abundante. Estas especificaciones de las materias primas cerraron puertas a la producción de acero básico en los hornos Siemens de Bilbao.

\section{CONCLUSIONES}

El objetivo de este trabajo era contrastar si la industria española pudo o no elegir producir para dos mercados, el nacional y el extranjero, lo que podía haber generado una industria más competitiva con economías de escala y precios de acero más bajos y una pieza menos en la posterior nacionalización de los mercados españoles. Hemos encontrado evidencia a favor de esta hipótesis: los productos de primera transformación tienen una ventaja comparativa frente a productos equivalentes de los centros de producción internacionales más eficientes del momento. Esta ventaja se justifica fácilmente con la abundancia del factor mineral de hierro y la intensidad de mineral de hierro con la que se producen esta clase de 
productos - tal y como lo predice el modelo de Heckscher-Ohlin. Pero encontramos que parte de la ventaja original de los productos intensivos en mineral de hierro, tanto para la fábrica de Baracaldo como para la de Sestao, residía especialmente en los contratos preferenciales de mineral. Estos contratos constreñían la expansión de la escala de producción de las fábricas y les inhibía, en el medio plazo, mantenerse a la altura de sus competidores extranjeros.

Existían otras alternativas para situar la siderurgia española entre los principales productores europeos. Desde mediados del siglo $\mathrm{xIX}$, la sustitución del carbón extranjero se apuntaba como estrategia muy atractiva para aumentar la competitividad de los productos españoles. El transporte desde Gran Bretaña o el resto de Europa venía aumentando el coste de los productos vizcaínos en una tercera parte. Pero encontrar sustitutivos nacionales apropiados en calidad y precio no fue viable. La mala calidad de los carbones nacionales y los elevados costes de transporte interior entorpecían el proceso de sustitución. Se consiguió mezclar pequeñas cantidades de carbones españoles a los carbones extranjeros, pero estas mezclas reducían de forma sustancial el rendimiento de los hornos y tenían unos niveles de tolerancia ahorro/calidad muy bajos.

Otra alternativa que examina el trabajo es ver en qué medida las empresas españolas podrían haber adoptado innovaciones que aumentaran la competitividad en el mercado mundial. En sus inicios, las dos factorías estudiadas pueden considerarse tecnológicamente a la altura de sus competidores internacionales y, a lo largo del periodo examinado, ambas introdujeron importantes cambios en sus instalaciones, siguiendo en cada momento las pautas de la siderurgia europea de vanguardia. En los departamentos de hornos altos realizaron inversiones que iban destinadas principalmente a aumentar la presión del aire inyectado a través de las toberas. Pero esta aplicación de la «marcha forzada» produjo un aumento muy moderado en el rendimiento de sus hornos altos. La producción de cada horno alto aumentó de unas 100 toneladas diarias hasta 200 toneladas, mientras que hornos de características parecidas en otros lugares del mundo producían $500 \mathrm{tm}$ diarias ${ }^{54}$. La siderurgia moderna española se presentó aquí como una industria innovadora, tecnológicamente a la altura de la

${ }^{54}$ Carr y Taplin (1962), pp. 403-404, dan promedios anuales nacionales para hornos altos en los Estados Unidos, 130.000 (356 tm/día); Alemania, 97.000 (266 tm/día), y el Sur de Gales, 97.600 (267 tm/día). Altos Hornos de Vizcaya producía un promedio de 36.000 toneladas al año por horno en activo $(99 \mathrm{tm} /$ día) e incluso en su momento más intenso sólo llegó a producir unas 54.000 toneladas ( $148 \mathrm{tm} /$ día) por horno. 
industria de vanguardia internacional, pero que no explotó el potencial de las economías que se ponía a su alcance.

En la transformación de hierro en acero, encontramos también infrautilizaciones de capacidad y de escalas manifiestas. La planta Bessemer con su diseño moderno hubiera permitido un rendimiento muy superior. Detectamos la misma insuficiencia para los hornos de acero Siemens. El hecho de que los convertidores Tropenas se mantuvieran en Sestao hasta 1914, veinticinco años después de que dejaran de estar vigentes los derechos de la patente Bessemer, y de que los turnos de noche no se introdujeran en Baracaldo hasta 1900, da indicios de que las empresas no querían - por motivos de colusión- o no podían - por las limitaciones que imponían sus contratos de minerales de hierro- minimizar costes con la aceleración de los flujos productivos.

Se demuestra que las fábricas vascas producían un lingote muy competitivo - apto para hacer acero Bessemer y a un precio de coste muy bajo-- La clave de la competitividad en productos intensivos en hierro crudo se encontraba en unos contratos preferenciales pero limitados de mineral de hierro. Esto constreñía su competitividad internacional a los niveles que les imponían sus contratos de mineral. Pero cabe subrayar que en ningún caso les impedía adoptar una estrategia dual como la que empleaban las empresas alemanas: vender barato fuera y más caro dentro del país con ayuda de un arancel. Las fábricas vascas podrían haber exportado perfectamente lo equivalente a sus cuotas de mineral en primeras transformaciones de hierro: lingote, tochos de acero, palanquilla, railes, etc. Y, por otro lado, podrían haber usado mineral a precios no preferenciales para producir lo que vendían en los mercados nacionales protegidos. Esto, como en el caso de Alemania, podía haberles permitido alcanzar las escalas de producción necesarias para competir internacionalmente en productos intensivos en hierro bruto y construir una industria siderúrgica europea de primera transformación importante.

¿Hasta qué punto era factible? Tenemos los ejemplos de las otras tres empresas europeas vinculadas por el mismo contrato preferencial de la Orconera. La empresa alemana Krupp superó la crisis económica alemana iniciada en 1873 con ventas al extranjero, estrategia que supo concentrar en la exportación de raíles a los Estados Unidos de América en los años noventa. Exportó el 64 por 100 de su producción entre 1879 y 1889 y el 33 por 100 entre $1890-1911^{55}$. Consett se especializó en la fabricación

"5rupp (1912), pp. 223-224. 
de planchas de hierro para la construcción naval, en los ochenta introdujo hornos Siemens para producir planchas y ángulos de acero y superó la crisis internacional repartiendo un dividendo promedio del 21 por 100 $(19,25 \text { por } 100 \text { de beneficio sobre capital empleado })^{56}$. Dowlais llevó a cabo fuertes inversiones en una planta nueva y en la modernización de sus talleres de laminación para mantenerse competitivo en el mercado de railes y planchas. Obtuvo, en promedio, unos beneficios brutos anuales de $£ 98.962$ en la década de los ochenta y de $£ 100.210$ en la de los noventa ${ }^{57}$. Aunque este trabajo no desvela las claves del éxito de estas otras empresas, sus trayectorias sujetas a las mismas limitaciones contractuales de mineral de hierro muestran que otro camino, diferente al elegido por Altos Hornos de Vizcaya, era posible.

Por último, el trabajo apunta que el origen de la captación de los mercados nacionales por parte de la empresa dominante, Altos Hornos de Vizcaya, podría residir en las limitaciones contractuales. Los elevados beneficios que aportaban, por un lado, la cartelización del sector y, por otro lado, el generoso margen de beneficio que implicaba producir dentro de la escala de los contratos preferenciales de mineral, dan una explicación alternativa a la actuación de la siderurgia española en este período.

\section{BIBLIOGRAFÍA}

ADARO MAGRO, Luis (1885): Informe sobre el carbón y el estado de la Marina de Guerra, Oviedo.

Altos Hornos de VIzCAya (1902): Escritura pública de constitución de la Sociedad Altos Hornos de Vizcaya, Bilbao, Casa de la Misericordia.

Alzola y Minondo, Pablo (1896): Memoria relativa al estado de la siderurgia en España, Bilbao.

ApraIz BarrIERo, José (1978): Fabricación de Hierro, Acero y Fundiciones, Bilbao, Urmo.

BAER, Werner (1969): The Development of the Brazilian Steel Industry, Vanderbilt University Press.

Barriero Zabala, Luis (1943): Estadística Minero-Siderúrgica de España, Bilbao, Casa Dochao.

BECK, Ludwig (1903): Die Geschichte des Eisens in technischer und kulturgeschichtlicher Beziehung, vol. 5, Braunschweig.

BurN, D. L. (1940): The Economic History of Steelmaking, 1867-1939. A Study in Competition, Cambridge University Press.

56 Warren (1990), capítulos 7 y 9 , y Richardson y Bass (1965).

57 Owen (1977), p. 91, y Edwards y Baber (1979), p. 150. El promedio de beneficios brutos entre 1856 y 1900 había sido $£ 90.347$. 
Burnham, T. H., y Hoskins, G. O. (1943): Iron and Steel in Britain, 1870-1930, London, Allen \& Unwin.

CARR, J. C., y TAPLIN, W. (1962): History of the British Steel Industry, Cambridge, Mass., Harvard University Press.

Churraca, A. (1951): Minería, industria y comercio en el País Vasco, San Sebastián.

DíAZ MORLÁN, Pablo (1999): «Los Ybarra Vizcaínos: origen y expansión de una dinastía empresarial (1801-1890)», Documento de trabajo, núm. 9908, Serie de Historia Económica, Fundación Empresa Pública.

Edwakds, J. R., y Baber, C. (1979): «Dowlais Iron Company: Accounting Policies and Procedures for Profit Measurement and Reporting Purposes», Accounting and Business Research, 9, pp. 139-151.

Escudero, Antonio (1998): Minería e industrialización de Vizcaya, Barcelona, Crítica.

- (1999): «Dos puntualizaciones sobre la historia de la siderurgia española entre 1880 y 1930», Revista de Historia Industrial, 15, pp. 191-200.

FELDENKIRCIEN, Wilfried (1982): Die Eisen- und Stablindustrie des Rubrgebiets, 1879-1914. Wachstum, Finanzierung und Struktur ibrer Grossunternebmer, Wiesbaden.

Fernández de Pinedo, Emiliano (1983): «Nacimiento y consolidación de la moderna siderurgia vasca (1849-1913) en el caso de Vizcaya», Información Comercial Española, 598, pp. 9-19.

- (1987): «La industria siderúrgica, la minería y la flota vizcaína a finales del siglo xIx. Unas puntualizaciones», en Mineros, sindicalismo y política, Oviedo, Fundación José Barreiro, pp. 149-177.

- (1988): «Factores técnicos y económicos en el origen de la moderna siderurgia y la flota vizcaína, 1880-1899», en E. FERNÁNDEZ DE PINEDO y J. L. HERNÁNDEZ (eds.), La industrialización en el norte de España, Barcelona.

- (1992): «Beneficios, salarios y nivel de vida obrero en una gran empresa siderúrgica vasca, Altos Hornos de Vizcaya (1902-1927). Una primera aproximación», Revista de Historia Industrial, 1, pp. 125-153.

Fernández-Miranda GuttérRez, Eustaquio (1925): La industria siderúrgica en Espa$\tilde{n} a$, Madrid, Comisión Protectora de la Producción Nacional.

Fraile Balbín, Pedro (1982): «El carbón inglés en Bilbao: una reinterpretación», Moneda y Crédito, 160, pp. 85-97.

- (1991): Industrialización y Grupos de Presión. La economía política de la protección en España, 1900-1950, Madrid, Alianza.

- (1992): Interés público y captura del Estado: la empresa pública siderírgica en España, 1941-1981, Documento de trabajo, núm. 9203, Fundación de Empresa Pública - Programa de Historia Económica.

Girona Rubio, Manuel (1989): Mineria y siderurgia en Sagunto, 1900-1936, Valencia, Alfons el Magnánim IVEI.

GonzÁlez Portilla, Manuel (1974): «El desarrollo industrial de Vizcaya y la acumulación de capital en el último tercio del siglo XIX», Anales de Economía, 24, pp. 43-83.

- (1981): La formación de la sociedad capitalista en el País Vasco (1876-1913), San Sebastián. 
- (1984): «Tecnología y productividad en la siderurgia española: el caso de Altos Hornos de Vizcaya, 1880-1936», en J. L. García Delgado (ed.), España, 1898-1936: Estructuras y Cambio. Coloquio de la Universidad Complutense sobre la España Contemporánea, Madrid, Universidad Complutense, pp. 71-89.

- (1985a): La Siderurgia Vasca (1880-1901). Nuevas tecnologías, empresarios y politica económica, Bilbao, Universidad del País Vasco.

- (1985b): «Las nuevas siderurgias vascas y los primeros sindicatos (cárteles) siderúrgicos (1886-1896)», en M. ARTOLA et ali., La España de la Restauración. Politica, economia, legislación y cultura. I Coloquio de Segovia sobre Historia Contemporánea dirigido por M. Tuñón de Lara, Madrid, Siglo XXI, pp. 153-169.

- (1993): «Producción y productividad en la siderurgia española», Ponencia presentado en el Congreso de la Asociación de Historia Económica de España en San Sebastián.

HARrison, Joseph (1976): «El coste de oportunidad del programa naval español de 1907: ¿Pantanos o acorazados?», Hacienda Pública Española, 38, pp. 111-122.

- (1983): «Heavy Industry, the State, and the Economic Development in the Basque Region, 1876-1936», Economic History Review, 36, 4, pp. 535-551.

Hogan, William T. (1971): Economic History of the Iron and Steel Industry in the United States, Lexington, Mass.

Houpt, Stefan (1998): «Cambio técnico y localización en la siderurgia española integrada, 1882-1936», Tesis doctoral, Universidad Carlos III Madrid.

- (2002): «Putting Spanish steel on the map: The location of Spanish integrated steel, 1800-1936», European Review of Economic History, 6, 2, pp. 193-220.

KENNEDY, William P. (1987): Industrial structure, capital markets and the origins of British economic decline, Cambridge, Cambridge University Press.

KRUPP (1912): Krupp 1812-1912. Zum 100jäbrigen Besteben der Firma Krupp und Gussstablfabrik zu Essen/Rubr, Jena, Gustav Fischer.

Martín ACEÑa, Pablo, y Comín, Francisco (1991): INI. 50 años de industrialización en España, Madrid, Espasa-Calpe.

MCCloskey, D. N. (1973): Economic Maturity and Entrepreneurial Decline. British Iron and Steel, 1870-1913, Cambridge, Mass., Harvard University Press.

NADAL, Jordi (1989): El fracaso de la revolución industrial en España, Barcelona, Ariel.

Nilsson, Carl Axel (1972): Järn ocb Stål I Svensk Ekonomi, 1885-1912. En Marknadstudie, Lund, Rahms Boktryckeri AB.

Nuwer, Michael (1988): «From Batch to Flow: Production Technology and Work-force Skills in the Steel Industry, 1880-1920», Tecbnology and Culture, pp. 808-838.

OKAZAKI, Tetsuji (1991): «Import Substitution and Competitiveness in the Prewar Japanese Iron and Steel Industry», en E. ABÉ e Y. SUzuKI (dir.), Changing Patterns of International Rivalry. Some Lessons from the Steel Industry, University of Tokyo Press, pp. 166-190.

Orconera Iron Ore Company Limited (s. f.): Segunda copia para la compañia Orconera Iron Company Limited del Contrato del ferrocarril y de explotación de varias minas, Bilbao, Urigüen Dochao. 
OWEN, John A. (1979): The History of the Dowlais Iron Works, 1759-1970, Newport, Starling.

París Egunaz, Higenio (1954): Problemas de la expansión siderírgica en España, Madrid, Instituto Sancho de Moncada.

Prados de la Escosura, Leandro (1995): «Spain's Gross Domestic Product, 1850-1993: Quantative Conjectures. Appendix», Working Paper, 95-06, Universidad Carlos III de Madrid.

Richardson, H. W., y Bass, J. M. (1965): «The Profitability of Consett Iron Company before 1914», Business History, 7, 2, pp. 73-96.

Rodríguez Alonso, J. (1902): Tratado de Siderurgia, Cádiz, Tipografía Gaditana.

SAÉZ GARCía, Miguel Ángel (1999): Alava en la siderurgia moderna española. San Pedro de Araya (1847-1935), Diputación Foral de Álava.

SÁnCHEZ Ramos, Francisco (1945): La economía siderúrgica española, Madrid, Instituto de Economía Sancho de Moncada.

Temin, Peter (1964): Iron and Steel in 19th century America, Cambridge, Mass., MIT Press.

Thomas, S. G., y Gilchrist, P. C. (1882): «The Manufacture of Steel and Ingot Iron from Phosphoric Pig-Iron», Iron, Supplement May 12, pp. 372-375.

Torres Villanueva, Eugenio (1998): Ramón de la Sota, 1857-1936. Un empresario vasco, Madrid, LID Empresarial.

WARREN, Kenneth (1990): Consett Iron 1840 to 1980. A Study in Industrial Location, Oxford, Clarendon Press.

WENGENROTH, Ulrich (1986): Unternebmensstrategien und Technischer Fortschriti, London, Vandenhoeck \& Ruprecht, English translation: (1993), Enterprise and technology: the German and British steel industries, 1865-1895, Cambridge, Cambridge University Press.

YBARRA E YBARRA, Javier de (2002): Nosotros, los Ybarra. Vida, economía y sociedad (1744-1902), Barcelona, Tusquets.

\section{FUENTES NO IMPRESAS}

Altos Hornos de Bilbao (1882): Copiador de Escrituras, Archivo Histórico de Altos Hornos de Vizcaya, Baracaldo.

- (1882-1901): Actas del Consejo de Administración, Archivo Histórico de Altos Hornos de Vizcaya, Baracaldo.

- (1882-1901): Memorias a las Juntas de Accionistas, Archivo Histórico de Altos Hornos de Vizcaya, Baracaldo.

- (1897, 1899-1901): Libros de contabilidad de costes, Archivo Histórico de Altos Hornos de Vizcaya, Baracaldo.

Altos Hornos De VizCAYa (1901-1936): Actas del Consejo de Administración, Archivo Histórico de Altos Hornos de Vizcaya, Baracaldo.

- (1901-1927): Libros de contabilidad de costes, Archivo Histórico de Altos Hornos de Vizcaya, Baracaldo.

CHÁVARRI, Víctor (1883): Memorias descriptivas de las instalaciones para una fábrica de bierro y acero proyectada en las marismas de Sestao por la Sociedad de Metalurgia y Construcciones Vizcaya, Archivo Histórico de Altos Hornos de Vizcaya. 
Dirección General de AduAnas (1869-1936): Estadísticas de comercio exterior de España, Biblioteca Delegación de Hacienda, c/Alcalá, 7, Madrid. Junta del Puerto de Bilbao (1887-1899): Memorias.

Sociedad de Metalurgia y Construcciones Vizcaya (1882-1901): Actas del Consejo de Administración, Archivo Histórico de Altos Hornos de Vizcaya, Baracaldo. 